University of Montana

ScholarWorks at University of Montana

$1-2001$

\title{
Ecological and Fitness Consequences of Species Coexistence: A Removal Experiment with Wood Warblers
}

P. R. Martin

Thomas E. Martin

University of Montana - Missoula, tom.martin@umontana.edu

Follow this and additional works at: https://scholarworks.umt.edu/wildbio_pubs

Part of the Life Sciences Commons

Let us know how access to this document benefits you.

\section{Recommended Citation}

Martin, P. R. and Martin, Thomas E., "Ecological and Fitness Consequences of Species Coexistence: A Removal Experiment with Wood Warblers" (2001). Wildlife Biology Faculty Publications. 15.

https://scholarworks.umt.edu/wildbio_pubs/15

This Article is brought to you for free and open access by the Wildlife Biology at ScholarWorks at University of Montana. It has been accepted for inclusion in Wildlife Biology Faculty Publications by an authorized administrator of ScholarWorks at University of Montana. For more information, please contact scholarworks@mso.umt.edu. 


\title{
ECOLOGICAL AND FITNESS CONSEQUENCES OF SPECIES COEXISTENCE: A REMOVAL EXPERIMENT WITH WOOD WARBLERS
}

\author{
Paul R. Martin ${ }^{1}$ And Thomas E. Martin ${ }^{2}$ \\ ${ }^{1}$ Montana Cooperative Wildife Research Unit, Avian Studies Program, University of Montana, \\ Missoula, Montana 59812 USA \\ ${ }^{2}$ United States Geological Survey, Biological Resources Division, Montana Cooperative Wildife Research Unit, \\ Avian Studies Program, University of Montana, Missoula, Montana 59812 USA
}

\begin{abstract}
Local guilds define groups of species that share common resources and coexist in space and time. Local guilds have historically been a major focus of community ecology; however, studies of local guilds rarely measure consequences of coexistence for fitness-related traits or test predictions of alternative hypotheses for how species may interact. We studied consequences of coexistence for Orange-crowned Warblers (Vermivora celata) and Virginia's Warblers ( $V$. virginiae), which have overlapping breeding territories in central Arizona. We used reciprocal removal experiments to examine (1) whether coexistence results in ecological consequences with respect to access to nest sites, access to food resources, nest predation, and adult female predation, and (2) whether ecological consequences result in fitness consequences with respect to reproductive success (clutch size, number of young fledged per nest), or adult female survival (within a breeding season). When we removed Virginia's Warblers, Orange-crowned Warblers experienced reduced nest predation rates compared with control plots where Virginia's Warblers were present. When we removed Orange-crowned Warblers, Virginia's Warblers (1) shifted their nest sites to sites indistinguishable from Orange-crowned Warbler nest sites, (2) increased feeding rates during both the incubation and nestling periods, and (3) suffered reduced nest predation rates, compared with control plots where Orange-crowned Warblers were present. When the two species coexist, increased nest predation rates for both species appear to result from density-dependent functional shifts in nest predator behavior (short-term apparent competition). Reduced access to preferred nest sites for Virginia's Warblers coexisting with Orange-crowned Warblers appears to result from both Orange-crowned Warbler interference during nest site selection and building periods, and from Orange-crowned Warbler preemption of nest sites preferred by both species. The mechanisms whereby Orange-crowned Warblers may reduce access to food resources for coexisting Virginia's Warblers, however, are not yet fully understood. Both Orange-crowned and Virginia's Warblers fledged between $78 \%$ and $129 \%$ more young per nest on plots where the opposite species had been removed, indicating that both species suffer substantial fitness costs of coexistence. Overall, results illustrate that (1) Orange-crowned and Virginia's Warblers do not coexist independently of each other, (2) interactions between the two species are complex and asymmetrical, (3) interactions between the two species result in substantial fitness costs of coexistence for both species, and (4) ecological interactions between the two species extend far beyond competition for food resources which has dominated studies of terrestrial vertebrate communities.
\end{abstract}

Key words: food limitation; habitat selection; indirect interactions; natural selection; nest predation; nest site limitation; resource partitioning; short-term apparent competition; species interactions; Vermivora celata; Vermivora virginiae; wood warblers.

\section{INTRODUCTION}

Local guilds define groups of species that share common resources (Fauth et al. 1996), and coexist in space and time and potentially interact (i.e., they are part of the same ecological community; McPeek and Miller 1996). Hypotheses examining consequences of coexistence for local guild members and how they partition resources historically have been a major focus of community ecology (e.g., Lotka 1925, Volterra 1926, Gause

Manuscript received 10 November 1998; revised 13 September 1999; accepted 28 September 1999.
1932, MacArthur 1958, Cody 1974, Schoener 1974, 1982, 1983, Diamond 1978, Tilman 1982, Connell 1983, Martin 1986, 1996, Wiens 1989a, b, Grace and Tilman 1990). Despite being a major focus, studies of interactions between local guild members rarely measure consequences of coexistence for fitness-related traits, or test predictions of alternative hypotheses for how species may interact (Connell 1980, Mac Nally 1983, Wiens 1983, 1989a, b, Martin 1986, Underwood 1986; see exceptions cited within these papers). Studies examining fitness consequences and alternative hypotheses for how species may interact have been no- 
ticeably rare in studies of terrestrial vertebrate fauna such as birds, even though these taxa have figured prominently in community ecology theory (e.g., MacArthur 1958, 1972, Diamond 1973, 1978, Cody 1974, Wiens $1989 a, b$ ).

Species within a local guild may coexist and use resources independent of any ecological interactions among each other (e.g., Gleason 1926, James et al. 1984). Alternatively, members of a local guild may interact ecologically, directly or indirectly influencing each other's patterns of resource use and acquisition, behaviors, and/or interactions with other species such as predators and parasites (e.g., Dobson and Hudson 1986, Grace and Tillman 1990, Bertness and Callaway 1994, Holt and Lawton 1994, Wooton 1994). These ecological interactions may or may not lead to fitness consequences for individuals through their influences on individual reproductive success and/or survival (e.g., Gustafsson 1987).

We chose two ecologically similar passerine birds to examine potential ecological and fitness consequences of coexistence for individuals of both species. Orangecrowned (Vermivora celata) and Virginia's ( $V$. virginiae) Warblers provide a perfect situation to examine ecological interactions and their consequences because they are well studied and are remarkably similar in their ecological strategies (nesting, foraging, shared predators) (Martin 1988a, b, 1993, 1996, 1998), providing an extreme along a gradient of ecological similarity within the local guild of insectivorous and/or opennesting birds. Given their ecological similarities, these two species provide the greatest potential for ecological interactions leading to fitness costs of coexistence within this local guild, and allow us to examine the importance of multiple potential ecological interactions between two coexisting species.

In this study, we used reciprocal removal experiments to examine the consequences of coexistence for Orange-crowned and Virginia's Warbler pairs. We compared pairs on control plots where the two species coexisted with pairs on experimental plots where the opposite species had been experimentally removed (hereafter, removal plots). We used comparisons to examine two questions addressing consequences of coexistence for Orange-crowned and Virginia's Warblers: (1) Does coexistence of Orange-crowned and Virginia's Warblers have ecological consequences (e.g., reduced access to resources, increased predation)? (2) Do these ecological consequences result in fitness consequences for individuals? Following we describe a priori hypotheses, predictions, and tests for these two questions.

\section{Does coexistence of Orange-crowned and Virginia's Warblers have ecological consequences?}

To address this question, we first reviewed evidence for a diverse array of ecological interactions that could potentially be important for coexisting Orangecrowned and Virginia's Warblers. Potential interactions include competition for resources and interactions mediated by predation and parasitism (Table 1). Evidence gathered to date suggests that parasitism on these two species is fairly rare on our study sites; however, both Orange-crowned and Virginia's Warblers use similar nest sites and food resources, and share the same nest and adult predators. Thus, from the potential ecological interactions outlined in Table 1, access to nest sites, access to food, nest predation, and adult predation seemed potentially important for coexisting Orangecrowned and Virginia's Warblers.

We tested predictions for each of the four potential ecological consequences of coexistence in both Orange-crowned and Virginia's Warblers. Throughout we predicted that if coexistence of these two species resulted in costs, then individuals on removal plots should experience reduced costs relative to individuals on control plots. If coexistence of the two species has ecological consequences for resource use, then we predicted that individuals on removal plots should shift their patterns of resource use towards those of the opposite species when compared with conspecific individuals on control plots.

If coexisting Orange-crowned and Virginia's Warblers influence each other's access to nest sites, then individuals on removal plots should shift their choice of nest site towards that of the opposite species compared with individuals on control plots. On our study plots, Orange-crowned Warblers typically nest lower in the drainages amidst a greater proportion of canyon maple (Acer grandidentatum) stems compared with Virginia's Warblers (Martin 1993, 1996, 1998). Virginia's Warblers typically nest higher on the drainages, and have a greater proportion of Gambel oak (Quercus gambellii) and New Mexican locust (Robinia neomexicana) stems compared with Orange-crowned Warblers (Martin 1993, 1996, 1998). Given these differences in nest sites, we predicted that if Virginia's Warblers influence access to nest sites for Orange-crowned Warblers, then Orange-crowneds nesting on removal plots (Virginia's Warbler removed) should place nests amidst more oak and locust stems, higher on the drainage compared with Orange-crowneds on control plots. Similarly, if Orange-crowned Warblers influence access to nest sites for Virginia's Warblers, then Virginia's nesting on removal plots (Orange-crowned Warbler removed) should place nests amidst more maple stems, lower on the drainage compared with Virginia's on control plots. If interactions between the two species are asymmetrical (e.g., Connell 1961, Bovbjerg 1970, Jaeger 1971 $a$, $b$, Griffis and Jaeger 1998), then we expected only one of the two species to shift their nest sites on removal plots compared with control plots.

We predicted similar responses for each of the remaining three factors. If coexisting Orange-crowned and Virginia's Warblers influence each other's (1) access to food, (2) nest predation, or (3) adult predation, then we predicted that pairs on removal plots should 
TABLE 1. Potential ecological consequences for coexisting Orange-crowned and Virginia's Warblers.

\begin{tabular}{|c|c|}
\hline Category & Consequences \\
\hline \multicolumn{2}{|l|}{ Limiting resources } \\
\hline Nest sites & $\begin{array}{l}\text { Orange-crowned and Virginia's Warblers both place their nests on the ground at the base of small } \\
\text { saplings (Martin 1993, 1996, 1998) and have been observed using the exact same nest sites in } \\
\text { different years (T. E. Martin and P. R. Martin, unpublished data). In addition, Orange-crowned } \\
\text { Warblers have been observed aggressively attacking female Virginia's Warblers during nest con- } \\
\text { struction (Martin and Martin 2001). }\end{array}$ \\
\hline Food & $\begin{array}{l}\text { Both Orange-crowned and Virginia's Warblers share similar foraging strategies (M. Jullien, unpub- } \\
\text { lished data), foraging substrates (M. Jullien, unpublished data), and feed nestlings a large propor- } \\
\text { tion of larval lepidoptera (T. E. Martin and P. R. Martin, unpublished data). In addition, foraging } \\
\text { speed of adults during nesting periods is at times quite high (M. Jullien, unpublished data), sug- } \\
\text { gesting that individuals of both species may be constrained in the amount of time available for } \\
\text { foraging. }\end{array}$ \\
\hline $\begin{array}{l}\text { Other limiting } \\
\text { resources }\end{array}$ & $\begin{array}{l}\text { Other studies have demonstrated limited roost sites, calcium, water, and other resources in various } \\
\text { avian systems (e.g., Graveland et al. 1994). We have no evidence to suggest similar limitations in } \\
\text { this system, and we do not suspect that these are important for interactions between coexisting } \\
\text { Orange-crowned and Virginia's Warblers. }\end{array}$ \\
\hline \multicolumn{2}{|l|}{ Predation } \\
\hline Nests & $\begin{array}{l}\text { Orange-crowned and Virginia's Warblers share the same nest predators on our study sites in central } \\
\text { Arizona (Martin 1988b, 1993; T. E. Martin and P. R. Martin, unpublished data), and thus these } \\
\text { two species could potentially interact through shared nest predators (Martin 1987, 1988a, 1988c, } \\
\text { 1996). In addition, artificial nest studies conducted at our study sites (Martin 1988a, 1996) have } \\
\text { shown increased nest predation rates with increased densities of ground nests. }\end{array}$ \\
\hline Adults & $\begin{array}{l}\text { Orange-crowned and Virginia's Warblers share the same adult predators on our study sites in central } \\
\text { Arizona (T. E. Martin and P. R. Martin, unpublished data), and thus these two species may poten- } \\
\text { tially interact through adult predation. }\end{array}$ \\
\hline Fledglings & $\begin{array}{l}\text { We have few data on predation of fledglings. However, Orange-crowned and Virginia's Warblers un- } \\
\text { doubtedly share the same fledgling predators on our study sites in central Arizona. Nonetheless, } \\
\text { fledgling predation was not examined in this study because accurate assessments of fledgling pre- } \\
\text { dation were not possible. }\end{array}$ \\
\hline \multicolumn{2}{|l|}{ Parasitism } \\
\hline Brood parasitism & $\begin{array}{l}\text { There were no cases of brood parasitism on our study plots during the period of our study (1996- } \\
\text { 1998). }\end{array}$ \\
\hline Nests & $\begin{array}{l}\text { No parasites were found within the nests of Orange-crowned and Virginia's Warblers on our study } \\
\text { sites (M. Revels, unpublished data), and thus this mechanism is not believed to be important in } \\
\text { mediating interactions between the two species. }\end{array}$ \\
\hline Ectoparasites & $\begin{array}{l}\text { Examination of carcasses of adult birds of both species for ectoparasites yielded no parasites. Simi- } \\
\text { larly, no ectoparasites have been found on nestlings or fledglings of these two species on our } \\
\text { study sites in Arizona. Thus, we believe that ectoparasites are an unlikely mechanism for ecologi- } \\
\text { cal interactions between the two species. }\end{array}$ \\
\hline $\begin{array}{l}\text { Endoparasites } \\
\quad \text { (including } \\
\text { disease) }\end{array}$ & $\begin{array}{l}\text { Examination of adult and nestling Orange-crowned and Virginia's Warblers for endoparasites (blood } \\
\text { parasites and parasites within the digestive tract) found endoparasites to be rare in these two spe- } \\
\text { cies (C. Olson and T. E. Martin, unpublished data). In addition, we have seen no evidence of } \\
\text { disease (e.g., pox) on Orange-crowned and Virginia's Warblers on our study sites. Thus, we be- } \\
\text { lieve that endoparasites are an unlikely mechanism for ecological interactions between these two } \\
\text { species. }\end{array}$ \\
\hline
\end{tabular}

(1) bring more food to their nests during the incubation period (rate of male feeding of incubating females on the nest) and nestling period (rate of nestling feeding), (2) experience reduced nest predation rates, and/or (3) experience reduced adult predation rates, compared with pairs on control plots. If interactions between the two species are asymmetrical, then we expected only one of the two species to demonstrate these responses.

\section{Do ecological consequences of coexistence result in fitness consequences for individuals?}

We next tested whether ecological consequences of coexistence in Orange-crowned and Virginia's Warblers resulted in fitness consequences for individuals of both species. If ecological consequences of coexistence resulted in fitness costs to individuals of either species, we predicted increased fitness for pairs on re- moval plots compared with pairs on control plots. In this study, we were unable to directly measure individual fitness of focal birds. Instead, we infer a fitness cost of coexistence if reproductive success measured to fledging is higher for pairs on removal plots compared with pairs on control plots, and/or if female survival through the nesting period is higher on removal compared with control plots.

Reproductive success.-To assess reproductive success, we measured fecundity (i.e., clutch size per nest), and the number of young fledged per nest. If coexistence of Orange-crowned and Virginia's Warblers exerts a cost, then females of both species on removal plots should lay more eggs (on average) and fledge more young compared with females on control plots. If interactions between the two species are asymmetrical, then only one of the two species should show 


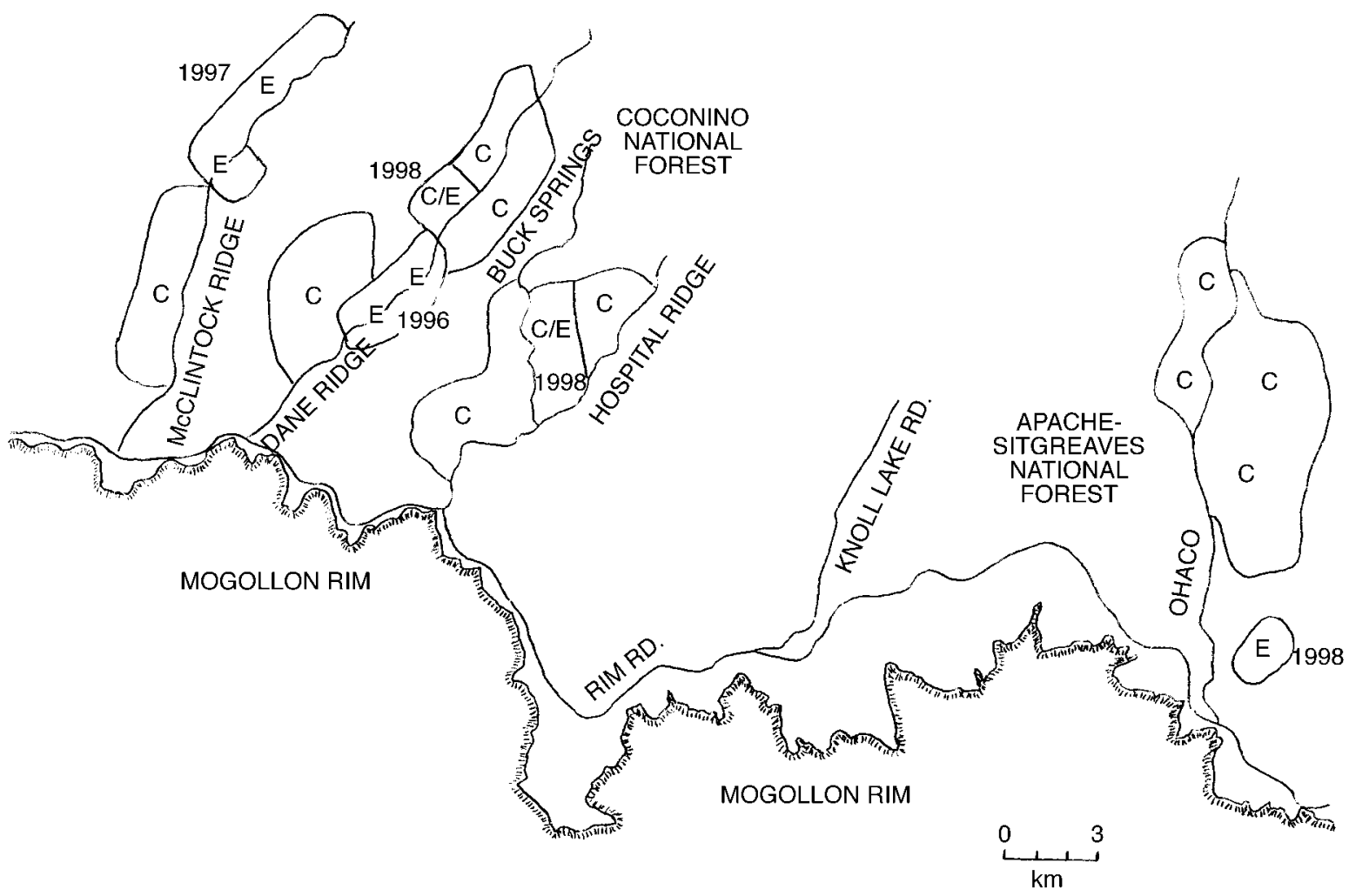

FIG. 1. Mogollon Rim study site, located $95 \mathrm{~km}$ southeast of Flagstaff, in central Arizona, USA. The same control plots were used in 1996, 1997, and 1998. Experimental removal plots differed between years. Control plots are marked as C; experimental plots are marked as E, and are identified by the year in which they were used. C/E refers to plots used as controls in 1996 and 1997, and as experimental removal plots in 1998.

increased clutch size and/or increased number of young fledged per nest on removal plots.

Survival.-If coexistence of Orange-crowned and Virginia's Warblers exerts a cost, then adults of both species on removal plots should show higher rates of survival through the nesting period compared with adults on control plots. If interactions between the two species are asymmetrical, then only one of the two species should show reduced adult predation rates on removal plots.

\section{Methods \\ Study area}

We studied Orange-crowned and Virginia's Warblers on snowmelt drainages located on the Mogollon Rim in central Arizona, USA $\left(34^{\circ} 25^{\prime} \mathrm{N}, 111^{\circ} 10^{\prime} \mathrm{W}\right)$ at $\sim 2300 \mathrm{~m}$ in elevation (Fig. 1). The forest within snowmelt drainages is comprised of quaking aspen (Populus tremuloides), Douglas-fir (Pseudotsuga menziesii), white fir (Abies concolor), ponderosa pine (Pinus ponderosa), southwestern white pine (Pinus strobiformis), and Gambel oak (Quercus gambellii). The understory vegetation was comprised primarily of canyon maple, New Mexican locust, saplings of overstory tree species, golden pea (Thermopsis pinetorum), raspberry (Rubus strigosus), and various grasses. Overall, the distribution of plant species varied across the width of the snowmelt drainages, with pine, oak, and locust dominating the upper slopes, and aspen and maple dominating the bottom of the drainages (Martin 1998). Forest surrounding the snowmelt drainages was characterized by open ponderosa pine with locust and oak in the subcanopy and little understory vegetation, and differed markedly from forest within the drainages (Martin 1998).

Prominent nest predators on our plots include red squirrel (Tamiasciurus hudsonicus), gray-collared chipmunk (Eutamias cinereicollis), and Steller's Jay (Cyanositta stelleri) (Martin 1988b, 1993, 1998). Adult and juvenile predators include Sharp-shinned Hawk (Accipiter striatus), Cooper's Hawk (A. cooperii), and Northern Goshawk (A. gentilis) (T. E. Martin and P. R. Martin, unpublished data). For more details on the study site and forest bird community, see Martin (1988b, 1993, 1998).

\section{Study species}

Orange-crowned and Virginia's Warblers are ecologically similar, closely related, oscine passerines in the family Parulidae (wood warblers). These two spe- 


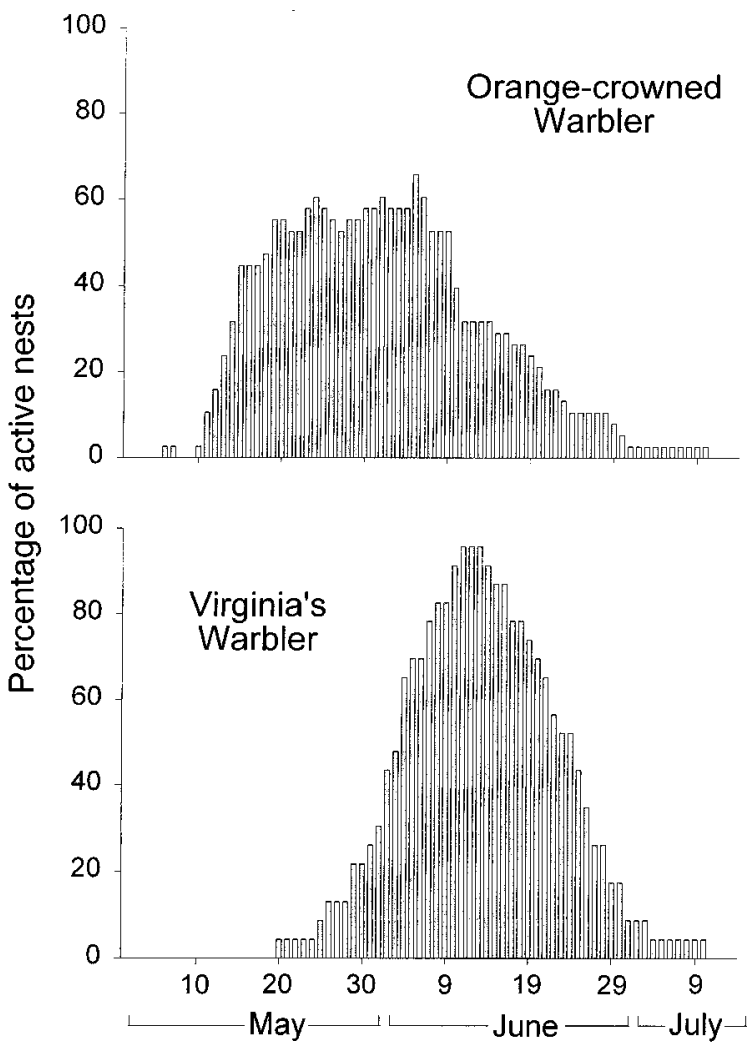

FIG. 2. Percentage of nests that were active for each day during the breeding season of 1997 (a typical year) for coexisting Orange-crowned Warblers and Virginia's Warblers on our study sites in central Arizona (control nests only). Orange-crowned Warblers commence breeding earlier, on average, compared with Virginia's Warblers, although the two species overlap breeding significantly. The graph includes renesting attempts following predation events, which are fairly common for Orange-crowned Warblers, but are infrequent for Virginia's Warblers. $N=38$ nests for Orange-crowned Warblers and 23 nests for Virginia's Warblers.

cies both nest on the ground, usually at the base of saplings, and both are predominately insectivorous on their breeding grounds, obtaining insects and other arthropods primarily by gleaning from foliage or by probing into leaf buds. Both species feed their young large amounts of lepidoptera larvae on our study sites in Arizona (T. E. Martin and P. R. Martin, unpublished data). Orange-crowned Warblers are heavier than Virginia's (9.0 g vs. 7.8 g, respectively; Dunning 1993), and dominate in aggressive interactions (Martin and Martin 2001). Orange-crowned Warblers arrive at the study sites in Arizona earlier on average than Virginia's Warblers, and commence nesting earlier in the season (Fig. 2). Both species, however, overlap nesting both temporally (Fig. 2) and spatially (Martin 1998: Fig. 1).

Orange-crowned Warblers differ from Virginia's ecologically, choosing moister, cooler habitats on average than Virginia's (Martin 2001). This is reflected by habitat use on all scales: Orange-crowned Warblers breed from Arizona to Alaska in the west and east across Canada to Labrador, while Virginia's are restricted to the drier, warmer southwestern United States (Scott 1987, Peterson 1990, Sogge et al. 1994, Dunn and Garrett 1997). Within their geographic range of overlap, Orange-crowned and Virginia's Warblers segregate elevationally: Orange-crowned Warblers are restricted to wet, cool, high-elevation forests (2290-3750 $\mathrm{m}$ in Arizona and New Mexico; 1830-2745 m in Colorado), while Virginia's are found through a variety of drier, warmer habitats, including pinyon-juniper forest, and dry oak-locust forest at lower elevations (1220$2745 \mathrm{~m}$ in Arizona and New Mexico; 1525-2135 m in Colorado; Bailey 1928, Ligon 1961, Andrews and Righter 1992, Sogge et al. 1994, Taylor 1995, Dunn and Garrett 1997). On a microhabitat scale, where Orange-crowned and Virginia's Warblers overlap territories, Virginia's Warblers choose nest sites higher up on the snowmelt drainage slopes where nest sites are warmer and drier, while Orange-crowned Warblers nest lower in the drainage where conditions are cooler and moister (Martin 1993, 1996, 1998, 2001).

Both species are migratory, with Orange-crowned Warblers wintering from the southern United States through to Mexico and Guatemala, and Virginia's Warblers wintering primarily in central Mexico (Dunn and Garrett 1997).

\section{Removal plots and methods}

We removed unpaired territorial male Orangecrowned Warblers or Virginia's Warblers from selected snowmelt drainages (Fig. 1) using a 22-caliber rifle with bird shot, or a .410-caliber shotgun with bird shot. Appropriate permits for these removals were provided by the U.S. Fish and Wildlife Service, Arizona Department of Game and Fish, and the University of Montana. Carcasses of birds were then collected and preserved for other studies. Males were removed primarily before female settlement in May and June 1996, 1997, and 1998, and females did not settle on plots where males were absent. On occasions where females settled before male removal, both individuals of the pair were removed. On two occasions, Orange-crowned Warbler pairs were not removed until after a nest site had been chosen and nest construction had begun. At this time, both members of the pairs were removed along with their nests. Resettlement after the initial removal of males was frequent (P. R. Martin and T. E. Martin, unpublished manuscript), and these subsequent males were also removed.

Birds were removed as soon as possible after arrival, generally from one to five days after first detection. In many cases, birds on removal plots encountered unpaired males of the opposite species. The amount of time that the two species interacted on removal plots, however, was significantly reduced compared with control plots, and no birds of the removal species bred on removal plots.

In 1998, we used Orange-crowned Warbler song 
playback as an alternative to lethal removals to exclude Orange-crowned Warblers from experimental removal plots. Orange-crowned Warbler song playback was broadcast continuously from the start of the dawn chorus (i.e., when most songbirds begin to sing in the morning before sunrise) for $5.5 \mathrm{hr}$ daily. We broadcast Orange-crowned Warbler song for $\sim 12 \mathrm{~d}$ on two experimental territories where Virginia's Warbler males were present. During extensive observations, four Orange-crowned Warblers (three males, one female) were observed on these territories for short periods, with a male Orange-crowned Warbler briefly countersinging with the song playback. In the end, however, no Orange-crowned Warblers settled on territories overlapping these two Virginia's Warblers territories.

Ideally in ecological experiments, experimental and control plots should be alternated to avoid potential plot effects on results (Hairston 1989). This was not always possible on our study sites as control plots are used for long term data collection (Martin 1988b, 1993, 1996, 1998; although we used some control plots as removal plots in 1998). Thus, we primarily chose adjacent or nearby snowmelt drainages with similar bird, predator, and plant assemblages for experimental removals, and subsequently tested for differences between control and removal plots. We used different experimental removal plots across years, even though densities of both species were comparable to preremoval densities on experimental plots the year following removals. In 1996 and 1997 only new experimental plots were chosen, while in 1998 we used several control plots from previous years as experimental removal plots, in addition to selecting new plots (Ohaco; Fig. 1).

We used individual snowmelt drainage plots as independent sample points in our analyses because territories of birds in different drainages were spatially separated from each other, and likely represent independent responses to our treatment. We calculated values for the variables of interest for each nest, and then calculated mean values across all nests located on each plot, and used these mean values in analyses. Many of the same control plots were used in different years. For analyses that lumped across years, we calculated mean values for variables of interest for each plot across years, by summing mean values for each year and dividing the sum by the number of years a given control plot was used. These overall means for each plot were then used in analyses. For analyses that lumped across species (i.e., when there were no significant differences between species or species $\times$ treatment effects), we calculated mean values for all nests of both species for each plot, and used these values in analyses.

Overall, we used a total of 20 experimental removal drainages and examined 25 experimental nests: seven experimental drainages in 1996 (two Virginia's removal, five Orange-crowned removal) with eight experimental nests (three Orange-crowned, five Virginia's); eight experimental drainages in 1997 (two Vir- ginia's removal, six Orange-crowned removal) with 11 experimental nests (three Orange-crowned, nine Virginia's); and five experimental drainages in 1998 (three Virginia's removal, two Orange-crowned removal) with six experimental nests (three Orange-crowned, three Virginia's). For comparison, we used 26-34 control drainages each year, with a total of 174 control nests: 67 control nests in 1996 (25 Orange-crowned, 42 Virginia's), 61 control nests in 1997 (38 Orange-crowned, 23 Virginia's), and 46 control nests in 1998 (31 Orangecrowned, 15 Virginia's).

All nests on removal plots were located between nest building and early incubation. Nests on control plots were located at various stages, from building to late nestling periods. Nests were located on all plots, primarily by following females to the nest. Once found, nests were monitored every $2-4 \mathrm{~d}$ on all plots until fledging of young, depredation by a predator, or abandonment by the parents.

\section{Plot effects}

We examined differences between control and removal plots with respect to relative abundance of nest predators, other ground-nesting passerine birds, and the general forest bird assemblage. In addition, we examined potential effects of shooting on nest predation rates in 1997.

Nest predator species.-Hi-8 mm video cameras were used to record incubation behavior at nests on control and experimental plots. Tapes were generally run simultaneously on control and experimental nests (except in 1998). We used the audio portions of these tapes for point counts, and recorded the number of red squirrel and Steller's Jay vocalizations heard from the tapes during a 30-min period from 0600-0630 MST. Predator vocalizations were recorded as independent if they were separated by at least $2 \mathrm{~s}$. We used the total number of vocalizations of these two prominent nest predators as an index of nest predator density and activity within the vicinity of these focal nests. Because we do not know the specific differences in vocalization rates relative to actual predator density, or the relative importance of squirrels or jays as nest predators, we standardized point count measurements of each species (i.e., squirrel or jay) by dividing the number of vocalizations heard during the $30 \mathrm{~min}$ by the mean value for all control plots during all years. We then summed standardized red squirrel and Steller's Jay values recorded on each plot to achieve a combined index of nest predator abundance. We square-root transformed these values $(1996,1998)$, and compared within years between control and removal plots using paired $t$ tests. Data from 1997 were analyzed using a Wilcoxon signed-rank test because transformed data did not conform to parametric assumptions. In all years, statistical tests tested the null hypothesis that nest predator abundance (as indexed by vocalizations) did not differ between control and removal plots. 
Ground-nesting species.-The density of ground nests has been shown to result in increased nest predation rates (Martin 1988a, 1996; see also Holt and Kotler 1987, Schmidt and Whelan 1998), and thus we examined differences between control and removal plots with respect to densities of the two other groundnesting passerine species on our study plots. Using the same videotape data as for nest predator surveys, we recorded whether or not Dark-eyed Junco (Junco hyemalis) or Red-faced Warbler (Cardellina rubifrons) were heard during the 30-min point count surveys for each plot. We then summed the total number of removal plots (within years) where juncos were present plus the total number of removal plots where Red-faced Warblers were present, and compared these values to identical values for control plots. We used chi-square goodness-of-fit tests for each year to test the null hypothesis that control and removal plots did not differ with respect to the numbers of ground-nesting species present.

Forest bird assemblage.-Using the same video data as for nest predator and ground-nesting passerine surveys, we recorded all of the bird species heard during the 30-min point count surveys. Within years, we dropped all species that were absent from $75 \%$ of the plots, and compared the overall frequencies of occurrence of the major forest bird species between control and removal plots. We used chi-square contingency tables for each year to test the null hypothesis that control and removal plots did not differ in their frequency of occurrence for other non-focal bird species.

Effects of shooting.-In 1997, we fired a .410-caliber shotgun six times on two different days on each of three control plots, and compared nest predation rates of ground nests on these plots with other nearby control plots. We used the program CONTRAST (Hines and Sauer 1989) to test the null hypothesis that shooting did not cause differences in nest predation rates between plots.

\section{Variables and analyses}

\section{Ecological consequences of coexistence.-}

1. Nest site vegetation.-For paired control and experimental nests, we measured the total number of oak, locust, and maple stems within a $5 \mathrm{~m}$ radius circle centered on the nest. We chose to measure these values because previous work has shown that Orange-crowned and Virginia's Warblers choose nest sites that differ with respect to the number and proportion of stems of these three species of trees (Martin 1993, 1996, 1998). Control and experimental nests were paired based on similar initiation dates $( \pm 1 \mathrm{~d}$; nest initiation defined as the day the first egg was laid), because weather and timing of nest initiation are known to influence nest site selection (Martin 2001). For cases where more than one control nest could be paired with an experimental nest (i.e., more than one control nest was initiated within one day of an experimental nest), we calculated a mean value for the control nests and used this value in our analysis. We calculated the relative proportions of maple vs. locust/oak within the $5 \mathrm{~m}$ radius, as (number of maple stems/[number of maple stems + locust stems + oak stems] $) \times 100$. This value provides the relative proportions of maple vs. locust/oak. High proportions of maple characterizes typical Orange-crowned Warbler nests, while high proportions of locust and oak are typical of Virginia's Warbler nests (Martin 1993, 1996, 1998). We tested whether Orange-crowned and Virginia's Warblers shifted their nest sites in response to removals of the opposite species by comparing the percentage of maple stems within a $5 \mathrm{~m}$ radius of their nests between control and removal plots. We used paired $t$ tests to test the two, one-tailed hypotheses that (1) Orange-crowned Warbler nests on removal plots will have a lower percentage maple compared with conspecific nests on control plots, and (2) Virginia's Warbler nests on removal plots will have a higher percentage maple compared with conspecific nests on control plots. It was not necessary to transform data prior to analyses.

2. Access to food: mate feeding rate (incubation).Paired control and experimental nests were videotaped for 4-6 h (0500-1200 MST) during the incubation period of nesting. Conspecific nests were paired based on identical clutch sizes. Nests were videotaped during the same time period (i.e., during the exact same time on the same day) where possible (in almost all nests in 1996 and 1997, but it was not possible in 1998) to alleviate influences of environmental variation on nest behaviors. We also attempted to control for stage of incubation by pairing control and experimental nests that were at the same stage $( \pm 2 \mathrm{~d})$, or by pairing control and experimental nests that were as close to the same stage as possible. When concurrent filming of nests was not possible, we filmed nests on days as close to each other as possible, on days with similar weather, and during identical times of the day. From videotapes, we recorded the total number of times the male visited the nest with food. Visits by the male usually resulted in males feeding females; however, in a few cases, males approached the nest with food when the female was off the nest. While males in these instances did not feed the females, we included these cases as attempted mate feeds and used them in our analyses. From the total number of successful and attempted mate feeds, we calculated hourly rates of mate feeding for both control and experimental nests for each paired sample of videotaped nests. We used paired $t$ tests to test the one-tailed hypothesis that males on removal plots have higher rates of mate feeding during incubation compared with males on control plots. Orange-crowned Warblers and Virginia's Warblers differed in their responses to the treatment, and thus were analyzed separately. Data were square-root transformed for Virginia's Warbler prior to analysis to normalize distribution.

3. Access to food: nestling feeding rates.-Paired control and experimental nests were videotaped for 4- 
$6 \mathrm{~h}$ (0500-1200 MST) during the nestling period. Conspecific control and experimental nests were paired based on having young at the same stage of development. Number of young present in the nest was also controlled, by pairing control and experimental nests with the same number of young. Videotaping nests during the same day was generally not possible. Thus, we typically filmed nests on days as close to each other as possible, on days with similar weather, and during identical times of the day. From videotapes, we recorded the total number of times the adults visited the nest with food. From the total number of trips with food, we calculated hourly nestling feeding rates for both control and experimental nests within a pair. While food load sizes may have differed between control and experimental pairs, we were unable to reliably estimate variation in food load size. Both Orange-crowned and especially Virginia's Warblers are shy around their nests, and video cameras could not be placed within range to accurately estimate the size of food loads. Thus, we compared only hourly feeding rates between paired control and experimental nests. We used paired $t$ tests to test the one-tailed hypothesis that pairs on removal plots will have higher hourly feeding rates compared with pairs on control plots. Orange-crowned and Virginia's Warblers differed in their responses to the treatment, and thus were analyzed separately. It was not necessary to transform data prior to analyses.

4. Nest-predation rates.-Both control and experimental nests were checked every two to four days, and the outcome of all nests was recorded as fledged, depredated, abandoned, or unknown. For nests where adults left dead eggs or young in the nest, the outcome was described as abandoned. For nests where young were present in the nests to a point of being capable of fledging (i.e., $10 \mathrm{~d}$ old, although some may fledge as early as $8 \mathrm{~d}$ old), and/or empty nests were matted down and feces were located on the nest wall, and/or fledglings were observed in the immediate vicinity of the nest, and/or the act of young fledging from the nest was observed, the outcome was described as successful fledging. For nests where eggs disappeared or nestlings disappeared before they were capable of fledging, and/ or empty nests or nest linings were torn up or removed, and/or fledglings could not be located near the nest shortly after they should have fledged and parents were not actively foraging at this time, the outcome was described as depredated. For any nest that did not fall into any of these categories, the outcome was described as unknown.

We examined differences in the proportion of nests depredated on control and removal plots in all years (combined), controlling for plot effects found in our study that were expected to potentially influence rates of nest predation (i.e., controlling for densities of both nest predators and other ground-nesting passerines; see Holt and Kotler 1987, Martin 1988a, 1996, Schmidt and Whelan 1998). For each plot, we calculated the proportion of nests depredated (across years), and used this as the dependent variable in a type III ANOVA. Sample sizes were unequal among treatments, which may increase the chance of type II error, but should not influence estimated marginal means or increase type I error (see Shaw and Mitchell-Olds 1993). Only nests found during the incubation period or earlier were used in the analysis to reduce any potential effects of stage on nest predation rates. We entered relative density of nest predators, relative density of other groundnesting passerines (i.e., Red-faced Warblers and Darkeyed Juncos), date of clutch initiation, and stage at which nests were found as covariates in the model, with treatment as the fixed factor. Covariates that did not approach significance $(P>0.10)$ in a first run of the model were subsequently dropped (i.e., the analysis was performed a second time without these covariates). Data were square-root transformed prior to analysis to normalize distribution. The proportion of nests depredated for Orange-crowned and Virginia's Warblers did not differ on either control or removal plots (see Results), and thus we lumped both species in all analyses of nest predation to increase power. We tested the one-tailed hypothesis that the proportion of nests depredated for both species will be lower on plots where the opposite species was removed, compared with control plots where the two species coexisted.

Analyses of nest predation rates usually use the methods of Mayfield (1975) to control for biases associated with unfound, depredated nests (by examining daily mortality rates instead of proportions of nests depredated). The disadvantage of this method is that analyses do not allow inclusion of covariates that may bias nest predation rates (e.g., plot effects described above). In our study, all nests for all females on removal plots were found (shortly after female settlement), and thus bias associated with unfound, depredated nests could only result in underestimates of predation rates on control plots. This makes our analysis more conservative with respect to our hypothesis (i.e., bias occurs in the opposite direction of our predictions), and also allows us to incorporate significant plot effects as covariates in our analysis.

For comparison, we also provide Mayfield estimates of daily mortality rates that do not control for plot effects. For this analysis, both the outcome of nests and duration that the nest was observed (exposure time) were recorded for each nest on control and removal plots. Nests were checked every two to four days, and the total number of days from the day the nest was discovered to the day the nest fledged or failed was recorded (i.e., number of exposure days). When abandonment or depredation occurred, we took the number of days between nest visits (when the event occurred) divided by two, and added this value to the total number of days the nest was observed. When fledging of young took place between nest visits, we used the stage of young at the last visit to assess the probable date of 


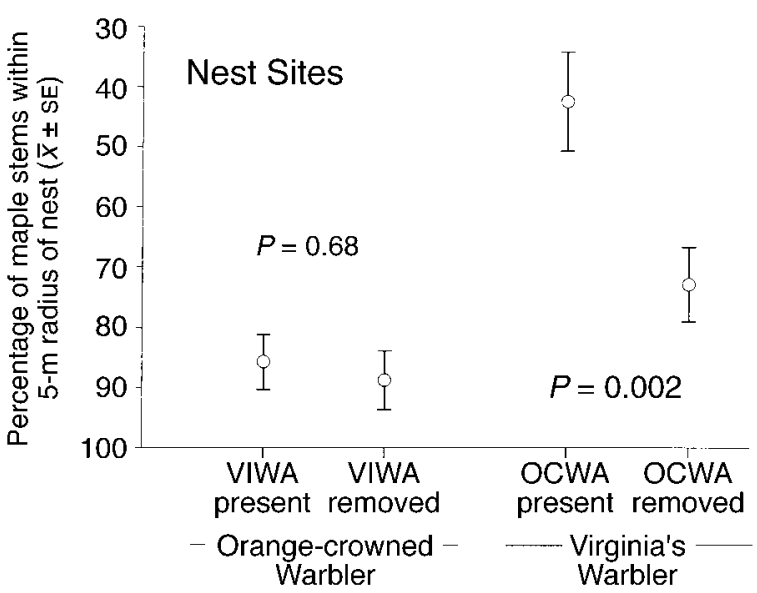

FIG. 3. Percentage of maple stems within a 5-m radius of Orange-crowned Warbler and Virginia's Warbler nests (mean $\pm 1 \mathrm{SE}$ ) on plots where the two species coexisted (opposite species present; control), compared with plots where the opposite species had been experimentally removed (opposite species removed). Two paired $t$ tests tested the one-tailed hypotheses that (1) Orange-crowned Warblers on plots where Virginia's Warblers had been removed would shift their nest sites to sites with less maple (i.e., to sites more similar to Virginia's Warbler nest sites), and (2) Virginia's Warblers on plots where Orange-crowned Warblers had been removed would shift their nest sites to sites with more maple (i.e., to sites more similar to Orange-crowned Warbler nest sites). See Table 2 for $t$ values, df, and sample sizes.

fledging, and calculated the number of days the nest was observed using this estimated fledging date. We subsequently estimated daily mortality rates of nests and their standard errors following Mayfield (1975), Johnson (1979), and Hensler and Nichols (1981). We used the program CONTRAST (Hines and Sauer 1989) to test for differences in predation rates on control vs. removal plots in each year, using only nests found during the incubation period or earlier to reduce any effects of stage on nest predation rates.

5. Female predation rates.-Given that adult predation is difficult to measure, we followed females with active nests to estimate daily mortality rates on nesting females. A female was assumed depredated if (1) her nest was depredated and the remains of the female were found near the nest; or (2) a nest with eggs or young was abandoned, the female could not be subsequently located, and the male increased song rates on its territory. Along with these data, we recorded the total number of days from the day the nest was discovered to the day the nest fledged or failed (i.e., number of exposure days) as described above for nest predation rates. We analyzed daily female predation rates using the Mayfield method described for Nest predation rates, above. Predation rates on Orange-crowned and Virginia's Warbler females did not differ, on either control or removal plots, and there were no significant differences between years. Thus, we lumped both species and all years together into one analysis. With these data, we tested the one-tailed hypothesis that female predation rates for both species will be lower on plots where the opposite species was removed compared with control plots where the two species coexisted. Predation appears to be the only source of mortality for adult Vermivora on our study sites (P. R. Martin and T. E. Martin, personal observations). Thus, this same analysis allowed us to test for treatment effects on adult female survival (i.e., 1 -daily mortality rates) through the breeding season.

Fitness consequences of coexistence.-

1. Clutch size.-Fecundity of females on control and removal plots was measured by counting the number of eggs in each nest after incubation had begun. We used a type III ANOVA to test the one-tailed hypothesis that females of both species should lay more eggs per nest, on average, on removal plots compared with control plots. Sample sizes were unequal among treatments, which may increase the chance of type II error, but should not influence estimated marginal means or increase type I error (see Shaw and Mitchell-Olds 1993). We controlled for the effects of date of nest initiation by including it as a covariate in the model. We then entered treatment as the sole fixed factor. Each species was examined separately because Orangecrowned and Virginia's Warblers differ in their mean clutch sizes (Martin 1995).

2. Number of young fledged.-Number of young fledged was recorded for all nests that were known to have fledged young (see Nest predation rates above for precise definitions). Number of young fledged from nests was calculated as the number of young recorded at the last visit to the nest, if the nest was known to have fledged. Only nests found during the incubation period or earlier were used in the analysis to reduce any effects of stage on nest predation rates. We used a type III ANOVA to test the one-tailed hypothesis that pairs of both species fledged more young per nest, on average, on removal plots compared with control plots. Sample sizes were unequal among treatments, which may increase the chance of type II error, but should not influence estimated marginal means or increase type I error (see Shaw and Mitchell-Olds 1993). Orange-crowned and Virginia's Warblers did not differ with respect to number of young fledged per nest on either control or removal plots (see Results), and thus we lumped both species in the analysis to increase power. We controlled for significant plots effects (relative density of nest predators, relative density of other ground-nesting passerines), and the effects of date of nest initiation and stage that the nest was found, by including them as covariates in the model (with treatment as the only fixed factor). Covariates that did not approach significance $(P>0.10)$ in a first run of the model were subsequently dropped (i.e., the analysis was performed a second time without these covariates). It was not necessary to transform data prior to analyses. 
TABLE 2. Mean values \pm 1 SE and statistical test results for measured characteristics of wood warbler pairs in control and removal plots.

\begin{tabular}{|c|c|c|c|}
\hline Variable measured & Control plots $\dagger$ & Removal plots $\dagger$ & Statistical results \\
\hline \multicolumn{4}{|l|}{ Nest Sites } \\
\hline \multicolumn{4}{|l|}{$\begin{array}{l}\text { Percentage maple } \\
\text { within } 5 \mathrm{~m} \text { of } \\
\text { nest }\end{array}$} \\
\hline Vermivora celata & $\begin{array}{l}85.76 \pm 4.59 \\
(7 \text { plots, } 9 \text { nests })\end{array}$ & $\begin{array}{l}88.79 \pm 4.88 \\
(7 \text { plots, } 9 \text { nests })\end{array}$ & $t=0.4, \mathrm{df}=6, P=0.68$ \\
\hline V. virginiae & $\begin{array}{l}42.49 \pm 8.24 \\
(11 \text { plots, } 17 \text { nests })\end{array}$ & $\begin{array}{l}72.82 \pm 6.14 \\
(11 \text { plots, } 17 \text { nests })\end{array}$ & $t=3.4$, df $=10, P=0.002 *$ \\
\hline \multicolumn{4}{|l|}{ Food } \\
\hline \multicolumn{4}{|l|}{ Mate feeding rate } \\
\hline V. celata & $\begin{array}{l}0.14 \pm 0.097 \\
(3 \text { plots, } 5 \text { nests })\end{array}$ & $\begin{array}{l}0.081 \pm 0.081 \\
(3 \text { plots, } 5 \text { nests })\end{array}$ & $t=0.3, \mathrm{df}=2, P=0.77$ \\
\hline V. virginiae $\ddagger$ & $\begin{array}{l}0.21 \pm 0.10 \\
(10 \text { plots, } 12 \text { nests })\end{array}$ & $\begin{array}{l}0.41 \pm 0.066 \\
(10 \text { plots, } 12 \text { nests })\end{array}$ & $t=2.4, \mathrm{df}=9, P=0.021^{*}$ \\
\hline \multicolumn{4}{|l|}{ Nestling feeding rate } \\
\hline V. celata & $\begin{array}{l}9.71 \pm 1.83 \\
(3 \text { plots, } 3 \text { nests })\end{array}$ & $\begin{array}{l}9.24 \pm 0.21 \\
(3 \text { plots, } 3 \text { nests })\end{array}$ & $t=0.2, \mathrm{df}=2, P=0.83$ \\
\hline V. virginiae & $\begin{array}{l}6.03 \pm 1.06 \\
(3 \text { plots, } 5 \text { nests })\end{array}$ & $\begin{array}{l}8.65 \pm 0.68 \\
(3 \text { plots, } 5 \text { nests })\end{array}$ & $t=3.2, \mathrm{df}=2, P=0.042^{*}$ \\
\hline \multicolumn{4}{|l|}{ Nest predation } \\
\hline 1996 & $\begin{array}{l}0.0475 \pm 0.0118 \S \\
(28 \text { plots, } 327 \text { exp. days } \|, 67 \\
\text { nests })\end{array}$ & $\begin{array}{l}0.00495 \pm 0.00680 \\
(5 \text { plots, } 107 \text { exp. days, } 7 \\
\text { nests })\end{array}$ & $X^{2}=9.8, \mathrm{df}=1, P=0.0009^{*}$ \\
\hline 1997 & $\begin{array}{l}0.0234 \pm 0.00894 \\
(20 \text { plots, } 286 \text { exp. days, } 61 \\
\text { nests })\end{array}$ & $\begin{array}{l}0.0677 \pm 0.0274 \\
(7 \text { plots, } 84 \text { exp. days, } 12 \\
\text { nests })\end{array}$ & $X^{2}=2.3, \mathrm{df}=1, P=0.13$ \\
\hline 1998 & $\begin{array}{l}0.0464 \pm 0.0135 \\
\text { (18 plots, } 243 \text { exp. days, } 42 \\
\text { nests) }\end{array}$ & $\begin{array}{l}0.00741 \pm 0.0104 \\
(4 \text { plots, } 68 \text { exp. days, } 5 \\
\text { nests })\end{array}$ & $X^{2}=5.2, \mathrm{df}=1, P=0.01^{*}$ \\
\hline \multirow[t]{5}{*}{$\begin{array}{l}\text { Overall ANOVA (all } \\
\text { years combined) } \mathbb{I}\end{array}$} & $\begin{array}{l}\text { density of nest predators } \\
\text { (covariate) }\end{array}$ & & $F=0.23, \mathrm{df}=1,40, P=0.63$ \\
\hline & $\begin{array}{l}\text { density of other ground-nest- } \\
\text { ing passerines (covariate)\# }\end{array}$ & & $F=4.0, \mathrm{df}=1,43, P=0.05$ \\
\hline & $\begin{array}{l}\text { date of clutch initiation } \\
\text { (covariate) }\end{array}$ & & $F=0.76, \mathrm{df}=1,40, P=0.39$ \\
\hline & $\begin{array}{l}\text { stage at which the nest was } \\
\text { found (covariate) }\end{array}$ & & $F=0.08, \mathrm{df}=1,40, P=0.77$ \\
\hline & treatment & & $F=8.9, \mathrm{df}=1,43, P=0.002 *$ \\
\hline \multicolumn{4}{|l|}{ Female predation $\dagger \dagger$} \\
\hline 1996 & $\begin{array}{l}0.00328 \pm 0.00311 \\
(28 \text { plots, } 339 \text { exp. days, } 67 \\
\text { females })\end{array}$ & $\begin{array}{l}0.00926 \pm 0.00922 \\
(6 \text { plots, } 108 \text { exp. days, } 8 \\
\text { females })\end{array}$ & \\
\hline 1997 & $\begin{array}{l}0.00927 \pm 0.00548 \\
(20 \text { plots, } 306 \text { exp. days, } 61 \\
\text { females })\end{array}$ & $\begin{array}{l}0.00398 \pm 0.00688 \\
(7 \text { plots, } 84 \text { exp. days, } 12 \\
\text { females })\end{array}$ & \\
\hline 1998 & $\begin{array}{l}0.00516 \pm 0.00446 \\
(18 \text { plots, } 258 \text { exp. days, } 42 \\
\text { females })\end{array}$ & $\begin{array}{l}0.00699 \pm 0.00985 \\
(4 \text { plots, } 72 \text { exp. days, } 6 \\
\text { females })\end{array}$ & \\
\hline All years combined & $\begin{array}{l}0.00540 \pm 0.00350 \\
(30 \text { plots, } 438 \text { exp. days, } \\
170 \text { females })\end{array}$ & $\begin{array}{l}0.00696 \pm 0.00512 \\
(17 \text { plots, } 263 \text { exp. days, } \\
26 \text { females })\end{array}$ & $X^{2}=0.06$, df $=1, P=0.80$ \\
\hline \multicolumn{4}{|l|}{ Clutch size } \\
\hline V. celata & $\begin{array}{l}4.46 \pm 0.12 \\
(25 \text { plots, } 70 \text { nests) } \\
\text { date of clutch initiation } \\
\quad \text { (covariate) } \\
\text { treatment }\end{array}$ & $\begin{array}{l}4.75 \pm 0.17 \\
(6 \text { plots, } 8 \text { nests })\end{array}$ & $\begin{array}{l}F=0.33, \mathrm{df}=1,28, P=0.57 \\
\boldsymbol{F}=\mathbf{1 . 3}, \mathbf{d f}=\mathbf{1}, \mathbf{2 8}, \boldsymbol{P}=\mathbf{0 . 1 3}\end{array}$ \\
\hline \multirow[t]{2}{*}{ V. virginiae } & $\begin{array}{l}3.45 \pm 0.085 \\
(24 \text { plots, } 64 \text { nests })\end{array}$ & $\begin{array}{l}3.54 \pm 0.16 \\
(9 \text { plots, } 15 \text { nests })\end{array}$ & $\Gamma-1.0, \mathrm{ur}-1,20, \Gamma-0.1 \mathrm{~J}$ \\
\hline & $\begin{array}{l}\text { date of clutch initiation } \\
\text { (covariate) } \\
\text { treatment }\end{array}$ & & $\begin{array}{l}F=17.2, \mathrm{df}=1,30, P< \\
\quad 0.0001^{*} \\
\boldsymbol{F}=\mathbf{0 . 5}, \mathbf{d f}=\mathbf{1}, \mathbf{3 0}, \boldsymbol{P}=\mathbf{0 . 4 8}\end{array}$ \\
\hline \multicolumn{4}{|c|}{ Number of young fledged per nest } \\
\hline 1996 & $\begin{array}{l}0.81 \pm 0.24 \\
(28 \text { plots, } 67 \text { nests })\end{array}$ & $\begin{array}{l}3.50 \pm 0.63 \\
(5 \text { plots, } 7 \text { nests })\end{array}$ & \\
\hline 1997 & $\begin{array}{l}1.73 \pm 0.34 \\
(20 \text { plots, } 61 \text { nests })\end{array}$ & $\begin{array}{l}0.50 \pm 0.50 \\
(7 \text { plots, } 12 \text { nests })\end{array}$ & \\
\hline 1998 & $\begin{array}{l}1.22 \pm 0.43 \\
(18 \text { plots, } 42 \text { nests })\end{array}$ & $\begin{array}{l}2.50 \pm 0.96 \\
(4 \text { plots, } 5 \text { nests })\end{array}$ & \\
\hline
\end{tabular}


TABle 2. Continued.

\begin{tabular}{|c|c|c|c|}
\hline Variable measured & Control plots $\dagger$ & Removal plots $\dagger$ & Statistical results \\
\hline \multirow{5}{*}{$\begin{array}{r}\text { Overall ANOVA (all } \\
\text { years combined) }\end{array}$} & density of nest predators & & $F=0.02, \mathrm{df}=1,40, P=0.88$ \\
\hline & $\begin{array}{l}\text { density of other ground-nest- } \\
\text { ing passerines (covariate)\# }\end{array}$ & & $F=12.15, \mathrm{df}=1,43, P=0.001^{*}$ \\
\hline & $\begin{array}{l}\text { date of clutch initiation (co- } \\
\text { variate) }\end{array}$ & & $F=0.47, \mathrm{df}=1,40, P=0.50$ \\
\hline & $\begin{array}{l}\text { stage at which the nest was } \\
\text { found (covariate) }\end{array}$ & & $F=0.72, \mathrm{df}=1,40, P=0.40$ \\
\hline & treatment & & $F=13.16, \mathrm{df}=1,43, P=0.0004 *$ \\
\hline
\end{tabular}

Notes: Sample sizes are reported in parentheses. Orange-crowned Warblers (Vermivora celata) and Virginia's Warblers ( $V$. virginiae) coexisted on control plots. On removal plots, the opposite species was experimentally removed. For variables where separate values for each species and/or year are not given, both species and/or all years were combined in the analysis (see Methods). All means and standard errors represent real values, not estimated marginal means from ANOVA models. See Figs. 6 and 7 for estimated marginal means and their standard errors from ANOVA models for nest predation and number of young fledged per nest, respectively. Results describing the overall treatment effect with respect to each variable are in boldface.

* Statistically significant at the alpha $=0.05$ level.

$\dagger$ Individual plot was the independent sample used in all analyses; however, many plots contained multiple nests.

$¥$ Square-root transformed prior to analysis to normalize distribution.

$\S$ Values are daily mortality rates of active nests; analyses do not control for significant plot effects in 1997.

|| Exposure days represent the sum of values across all plots; values for each plot are the mean values for all nests on that plot.

II ANOVA examined proportion of nests depredated (square-root transformed) and controlled for plot effects (see appropriate covariates)

\# Relative densities of Dark-eyed Junco (Junco hyemalis) and Red-faced Warbler (Cardellina rubifrons) on plots.

$\dagger \dagger$ Values are daily mortality rates of nesting females within a breeding season.

3. Female survival.-See Female predation rates above.

\section{Corrections for multiple comparisons}

In this study, a correction for multiple comparisons (simultaneous-inference significance) was not used because data were collected from independent observations. If we follow Rice (1989) and correct for multiple tests testing the same null hypothesis (e.g., reduced access to food for Virginia's Warbler, two tests), the significance of results reported below remains unchanged (i.e., all significant $P$ values remain significant at $P<0.05)$ after sequential Bonferroni corrections (using methods of Hochberg 1988 or Rice 1989). If we apply the same sequential Bonferroni corrections to nonindependent, functionally related variables (e.g., nest predation rates which influence the number of young fledged per nest), the significance of results reported below again remains unchanged (i.e., all significant $P$ values remain significant at $P<0.05)$ despite the fact that such tests are overconservative for correlated variables (James 1991).

\section{RESUlts \\ Plot effects}

Nest predator species.-Nest predator densities did not differ significantly between control and removal plots in 1996 or 1998 ( $P>0.25$ in both years), but differences approached significance in $1997(Z=-1.8$, $P=0.075$ ), with 1997 removal plots having over twice the mean relative density of nest predators as 1997 control plots.
Ground nesting species.-Occurrence of Dark-eyed Juncos and Red-faced Warblers combined did not differ between control and removal plots in 1996 or 1998 ( $P$ $>0.25$ in both years); however, juncos and Red-faced Warblers were more abundant on removal plots compared with control plots in $1997\left(X^{2}=4.6\right.$, df $=1, P$ $=0.03$ ).

Forest bird assemblage.-Occurrence of major forest bird community species (i.e., species present in $>25 \%$ of all censuses within years) did not differ between control and removal plots in any of the three years $(P>0.25$ for all years $)$.

Effects of shooting.-We found no difference $(P>$ 0.25 ) in predation rates on ground nests between control plots with shooting vs. control plots without shooting.

\section{Removal experiments}

Ecological consequences of coexistence.-

1. Nest site vegetation.-Vegetation of Orangecrowned Warbler nest sites on control plots, where Virginia's Warblers coexisted, did not differ from plots where Virginia's Warblers had been experimentally removed (Fig. 3; Table 2). Nests of Virginia's Warblers on plots where Orange-crowned Warblers had been experimentally removed, however, were placed amidst a greater proportion of maple compared with Virginia's nest sites on control plots, where the two species coexisted (Fig. 3; Table 2). Of 17 Virginia's Warbler nests on removal plots, 13 (76\%) were shifted into mapledominated vegetation, with consistent results (70-80\% of nests) across all three years of the study. Overall, 


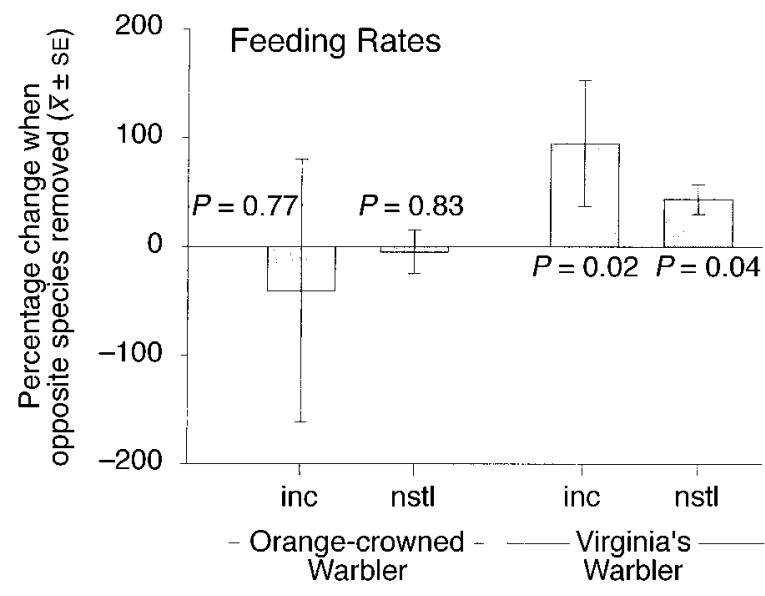

FIG. 4. Percentage difference in feeding rates (mean \pm 1 $\mathrm{SE})$ at Orange-crowned Warbler and Virginia's Warbler nests on plots where the two species coexisted (control), and on plots where the opposite species had been experimentally removed. Values represent ([experimental nests - control nests $] /$ mean value for control nests) $\times 100$ (i.e., the percentage "change" in feeding rates when the opposite species was removed). Feeding rates were measured during incubation (inc) (rates of male feeding of incubating females on the nest), and during the nestling period (nstl) (nestling feeding rates by both parents). $P$ values are from paired $t$ tests testing the one-tailed hypotheses that Orange-crowned and Virginia's Warblers fed more on plots where the opposite species was removed. See Table 2 for $t$ values, df, and sample sizes. Virginia's Warbler mate feeding rate was square-root transformed prior to analysis to normalize data (values in figure are untransformed).

Virginia's Warbler nests on removal plots were placed in sites indistinguishable from Orange-crowned Warbler nest sites ( $t$ test, $P>0.10$ ) (Fig. 3).

2. Access to food.-Orange-crowned Warbler feeding rates (both rates of male feeding of incubating females and nestling feeding rates) did not differ between control plots where Virginia's Warblers coexisted and removal plots where Virginia's Warblers had been experimentally removed (Fig. 4; Table 2). Virginia's Warblers, however, increased both rates of male feeding of incubating females, and nestling feeding rates on plots where Orange-crowned Warblers had been experimentally removed compared with control plots (Fig. 4; Table 2). Increases in feeding rates on removal plots were evident despite small sample sizes (particularly for the nestling period), and represented mean increases of $\sim 95 \%$ in mate feeding of incubating females (incubation period), and $43 \%$ in nestling feeding by both parents (Fig. 4; Table 2).

3. Nest predation rates.-In two out of three years (1996 and 1998), nest predation rates were significantly lower on plots where the opposite species had been removed compared with control plots (Table 2). In 1997, nest predation rates did not differ between control and removal plots (Table 2), and may have been influenced by plot effects with respect to nest predator density and density of other ground-nesting passerines (see Plot effects above). Indeed, relative density of all ground-nesting passerines combined showed a positive relationship with the proportion of nests depredated that approached significance $\left(F_{1,4}=4.1, P=0.056\right.$; Fig. 5; one-tailed test), while the relative density of nest predators explained little variance associated with the proportion of nests depredated $\left(r^{2}=0.06, F_{1,4}=\right.$ $0.24, P=0.65$; one-tailed test). These relationships suggest that plot effects found in 1997, at least with respect to the relative density of other ground-nesting passerines, may bias analyses of nest predation rates (and reproductive success to fledging) that do not control for plot effects (Table 2). In our analysis controlling for plot effects (all years combined), we found that the proportion of nests depredated was approximately $52 \%$ lower on removal plots compared with control plots (Fig. 6), and treatment effects were significant overall (Table 2).

Both Orange-crowned and Virginia's Warblers showed the same pattern (species effect, $F_{1,54}=1.4, P$ $=0.24$; species $\times$ treatment effect, $F_{1,54}=0.48, P=$ $0.49)$, and results approached significance $(P<0.10)$ if species were analyzed separately. In accordance with Fig. 5, the relative density of other ground-nesting species was the only covariate in the model to approach significance (Table 2). Results were not affected by unequal sample sizes of the treatments. If we collapse values for adjacent control plots (by taking the mean value) until the sample sizes of control and removal plots are equivalent $(N=16,16)$, results are identical but stronger for the significant variables (see Shaw and Mitchell-Olds 1993; density of ground-nesting passerines, $F_{1,29}=12.4, P=0.001$; treatment $F_{1,29}=21.2$, $P<0.0001)$.

4. Female predation rates.-In all three years combined, female predation rates did not differ between control plots where Orange-crowned and Virginia's Warblers coexisted and experimental plots where the opposite species had been removed (Table 2). During this time, a total of 12 female predation events were observed, with all female predation occurring away from the nest.

Fitness consequences of coexistence.-

1. Fecundity.-Clutch sizes of nests for both species did not differ between plots where the opposite species had been removed compared with control plots where the two species coexisted (Table 2). While there was no real trend for Virginia's Warbler clutch sizes, Orange-crowned Warbler clutch sizes varied in the predicted direction, although differences between treatments were relatively small (Table 2). Results were not affected by unequal sample sizes of the treatments. If we collapse values for adjacent control plots (by taking the mean value) until the sample sizes of control and removal plots are equivalent (Virginia's $N=9,9$; Orange-crowned $N=6,6$ ), results are identical to those obtained with unequal sample sizes (see Shaw and Mitchell-Olds 1993). 


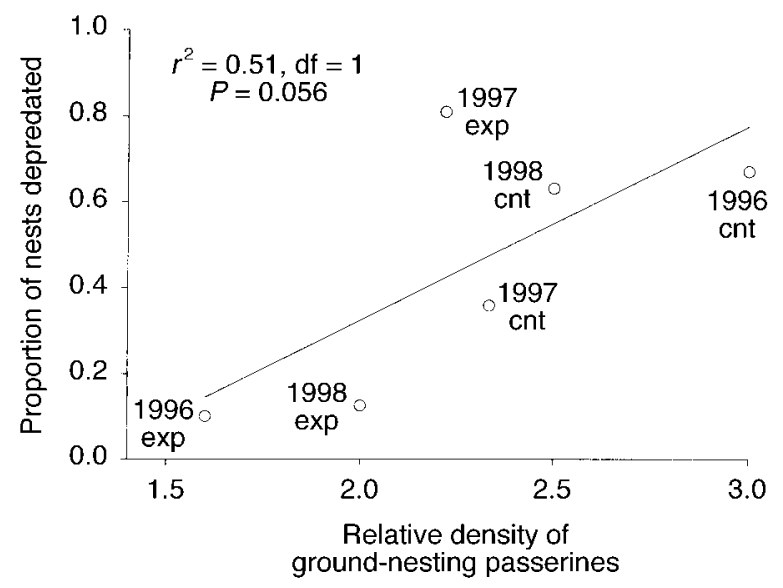

FIG. 5. Relationship between the relative density of ground-nesting passerines (i.e., combined densities of Orange-crowned, Virginia's Warblers, Red-faced Warblers, and Dark-eyed Juncos) and the proportion of Orange-crowned and Virginia's Warbler nests (combined) that were depredated. See Discussion for potential plot effects on 1997 experimental removal plots. The relationship described by the regression line is $y=-0.576+0.451 x$. Points represent mean values for control and experimental removal plots for each year of the study. Excluding 1997 removal plots, $r^{2}=0.85$, $P=0.01(y=-0.706+0.474 x)$. See Results for $F$ values and $\mathrm{df}$.

2. Number of young fledged.-Nests on plots where the opposite species had been removed fledged significantly more young per nest, on average, compared with nests on control plots where the two species coexisted (Table 2, Fig. 7). Nests of both species on removal plots fledged, on average, $>1.5$ additional nestlings per nest, a $129 \%$ increase over the mean number of young fledged per nest on control plots (based on estimated marginal means from ANOVA model controlling for plot effects, examining all years combined; Table 2, Fig. 7). Similarly, when we examine unadjusted values for 1996 and 1998 (excluding 1997 because of plot effects; see Results: Plot effects), we find nests of both species fledged approximately one additional nestling on removal plots, a $78 \%$ increase in the number of young fledged per nest compared with control plots.

Both species showed the same pattern with respect to the number of young fledged per nest (species effect, $F_{1,54}=0.02, P=0.89$; species $\times$ treatment effect, $F_{1,54}$ $=0.40, P=0.53)$, and results approached significance $(P \leq 0.05)$ if species were analyzed separately. Analysis of the number of young fledged per nest controlled for plot effects with respect to the relative densities of both nest predators and other ground-nesting passerines (i.e., Red-faced Warblers and Dark-eyed Juncos). Only the relative density of other ground-nesting passerines was a significant covariate (Table 2), as was expected from the observed relationships between density of ground-nesting passerines and the proportion of nests depredated (Fig. 5). Results were not affected by un- equal sample sizes of the treatments. If we collapse values for adjacent control plots (by taking the mean value) until the sample sizes of control and removal plots are equivalent $(N=16,16)$, results are identical but stronger for the significant variables (see Shaw and Mitchell-Olds 1993; density of ground-nesting passerines, $F_{1,28}=16.3, P<0.0004$; treatment $F_{1,28}=17.0$, $P<0.0002)$.

\section{DISCUSSION}

Reciprocal removal experiments of Orange-crowned and Virginia's Warblers in central Arizona revealed that ecological interactions between the two species are complex, and extend far beyond competition for food that historically has been the focus of vertebrate local guild studies (e.g., MacArthur 1958, Cody 1974, Schoener 1974, 1983, Cody and Diamond 1975, Diamond 1978). On plots where Virginia's Warblers were experimentally removed, the behaviorally dominant Orange-crowned Warbler experienced reduced nest predation rates compared with plots where the two species coexisted (Fig. 6). Orange-crowned Warblers did not, however, shift nest site placement (Fig. 3) or show evidence of increased food brought to the nest (Fig. 4) when Virginia's Warblers were removed. On plots where Orange-crowned Warblers were experimentally removed, the behaviorally subordinate Virginia's Warbler shifted nest sites to sites indistinguishable from Orange-crowned Warbler nest sites (Fig. 3), brought in more food to the nest during incubation and nestling

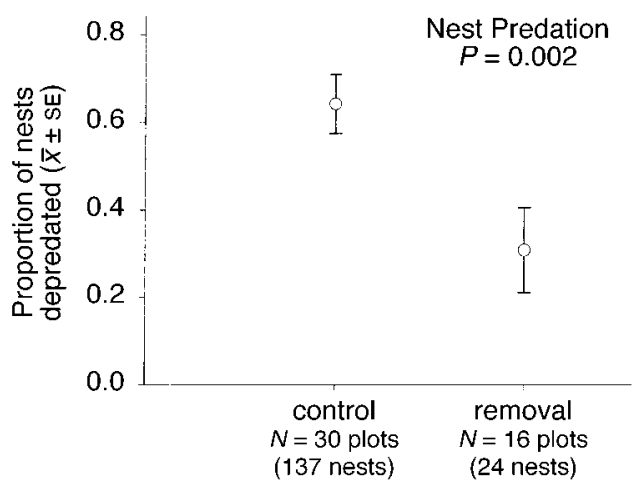

FIG. 6. Proportion of nests that were depredated (mean $\pm 1 \mathrm{SE}$ ) for pairs of Orange-crowned Warblers and Virginia's Warblers (combined) on plots where the two species coexisted (control), compared with plots where the opposite species had been experimentally removed (removal). Statistics represent summaries from a type III ANOVA (see Table 2). Values represent estimated marginal means and their standard errors calculated from the ANOVA model, controlling for plot effects with respect to the relative density of other groundnesting passerines (i.e., Red-faced Warblers and Dark-eyed Juncos; see Table 2, Methods). The reported $P$ value is onetailed, testing the a priori prediction that nests on plots where the opposite species had been removed would experience lower rates of predation. See Table 2 for $F$ values and df, and for separate analyses by year using daily mortality rates and Mayfield methods. 


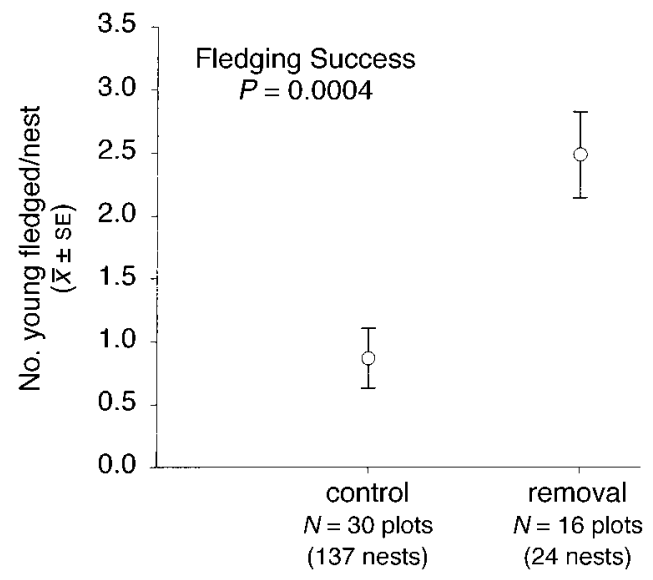

FIG. 7. Number of young fledged per nest (mean $\pm 1 \mathrm{SE}$ ) for pairs of Orange-crowned Warblers and Virginia's Warblers (combined) on plots where the two species coexisted (control), compared with plots where the opposite species had been experimentally removed (removal). Statistics represent summaries from a type III ANOVA (see Table 2). Values represent estimated marginal means and their standard errors calculated from the ANOVA model controlling for plot effects with respect to the relative density of other groundnesting passerines (i.e., Red-faced Warblers and Dark-eyed Juncos). The reported $P$ value is one-tailed, testing the a priori prediction that pairs on plots where the opposite species had been removed would fledge, on average, more young per nest. See Table 2 for $F$ values and df.

periods (Fig. 4), and experienced reduced nest predation rates (Fig. 6), when compared with plots where the two species coexisted. While neither species showed reduced predation rates on females (Table 2) or significant changes in fecundity (Table 2) when the opposite species was removed, both species showed significant increases in reproductive success (number of young fledged per nest; Fig. 7) suggesting that coexistence of Orange-crowned and Virginia's Warblers results in substantial fitness costs to both species.

\section{Nest sites}

In the absence of Orange-crowned Warblers, Virginia's Warblers showed a dramatic shift in nest site use, from hot, dry, locust/oak-dominated nest sites to cooler, moister sites in maple, indistinguishable from nest sites typically occupied by Orange-crowned Warblers (Fig. 3). Additional evidence suggests that Orange-crowned Warblers may reduce Virginia's Warbler access to preferred maple nest sites by (1) aggressively interfering with Virginia's Warblers attempting to select or build in maple sites, and (2) preempting these sites, making them unavailable to later arriving Virginia's Warblers. Observations of Orange-crowned Warblers attacking building female Virginia's Warblers (even knocking nesting material out of their bills), as well as general aggression of Orange-crowned Warblers towards Virginia's early in the breeding season (Martin and Martin 2001), support the hypothesis that Orange-crowned Warblers may exclude Virginia's from preferred nest sites through direct aggressive interference. In addition, two Orange-crowned Warblers were not removed from experimental plots until nests were being constructed (see Methods). At that time, both members of the pair and their nests were removed, and the nest depression was filled with leaves. Virginia's Warblers subsequently settled on both of these territories, and on one territory, a Virginia's nest was built in the exact same nest site as was selected by the Orange-crowned Warbler pair. While Virginia's Warblers occasionally use old Orange-crowned Warbler nest sites on our study plots (T. E. Martin and P. R. Martin, unpublished data), this is the first evidence of a preferred nest site being unavailable to a Virginia's Warbler pair because it was already occupied by Orange-crowned Warblers on an overlapping territory. Detailed work on nest site choice in these species illustrates that nest sites differ from other superficially-similar sites within breeding territories (Martin 1998). This suggests that nest sites are carefully chosen and may well be a limiting and important resource for these and other open-cup nesting species (see also Calder 1973, Walsberg 1981, Martin and Roper 1988, Martin 1996, 1998).

\section{Food}

When Orange-crowned Warblers were experimentally removed, Virginia's Warblers made more trips to the nest with food, both during the incubation period (male feeding of incubating females), and during the nestling period (both parents feeding nestlings; Fig. 4). Potential mechanisms by which Orange-crowned Warblers may restrict Virginia's access to food are diverse, and how this may occur in nature is not fully understood. Female Virginia's Warblers on removal plots devoted less time to brooding their young (P. R. Martin and T. E. Martin, unpublished data), suggesting that altered time budgets that may result from other factors (e.g., shifted nest sites located in more favorable microclimatic conditions; see discussion in Walsberg 1985; see also Zerba and Morton 1983) may underlie increased feeding rates during the nestling period. Limited data also suggest that Virginia's Warblers may have higher foraging success on removal plots compared with control plots (M. Jullien, unpublished data), and thus other factors such as interference or exploitative competition for food may also help to explain reduced access to food for Virginia's Warblers coexisting with Orange-crowned Warblers.

\section{Nest predation}

In two of three years, Orange-crowned and Virginia's Warblers experienced significantly higher nest predation rates on control plots, where the two species coexisted, compared with removal plots, where the opposite species had been removed (Table 2). In 1997, we observed no significant effect of treatment on nest predation rates (Table 2), which we attribute to higher densities of other ground-nesting passerines (and pos- 
sibly, in part, due to higher densities of nest predators) on 1997 experimental plots (see Results: Plot effects). The relative density of all ground-nesting passerines was found to positively covary with nest predation (Fig. 5), a relationship that has been suggested by a variety of studies (e.g., Holt and Kotler 1987, Martin $1988 a, 1996$, Schmidt and Whelan 1998). When we controlled for plot effects with respect to differences in densities of other ground-nesting passerines (Table 2 ), overall treatment effects were significant, with $52 \%$ fewer nests depredated on removal plots compared with control plots (Fig. 6, Table 2).

A variety of evidence suggests that the higher nest predation rates observed when Orange-crowned and Virginia's Warblers coexist may result from nest predator response to an increased density of ground nests. First, both Orange-crowned and Virginia's Warblers showed similar decreases in nest predation rates when the opposite species was removed, in spite of behavioral asymmetries between the two species (Martin and Martin 2001). This suggests that increased nest predation rates when Orange-crowned and Virginia's Warblers coexist do not result from direct interactions between the two species. Second, Orange-crowned Warblers did not alter time budgets during the nestling periods (for e.g., time spent incubating, brooding) when Virginia's Warblers were removed (P. R. Martin and T. E. Martin, unpublished data), suggesting that increased nest predation rates when the two species coexist do not result from any interactions between parental behaviors and nest predation. Third, the total density of ground-nesting passerines on control and removal plots in each year is positively correlated with the proportion of Vermivora nests depredated (Fig. 5), suggesting a potential causal relationship between nest density and nest predation. Finally, previous artificial nest experiments that simulated Orange-crowned and Virginia's Warbler nests on our study sites, found increased nest predation rates that coincided with an increase in the density of ground nests, independent of parental behavior (Martin 1988a, 1996).

Together, this evidence strongly suggests that nest predation rates increase when Orange-crowned and Virginia's Warblers coexist because of an increase in the density of ground nests. Nest predation rates may increase with increased nest density through (1) numerical responses of nest predators to increased densities of prey (i.e., ground nests; "apparent competition," Holt 1977), or (2) functional responses of nest predators (e.g., shifts in foraging behavior) to increased densities of prey ("short-term apparent competition," Holt and Kotler 1987, Martin 1987, 1988a, c, 1996, Schmidt and Whelan 1998). A numerical response of nest predators is unlikely given that primary nest predators have reproductive cycles too long to respond to changes in nest density (Walker 1964, Greene et al. 1998), and nest predator abundance did not positively correlate with relative density of ground-nesting pas- serines $(r=-0.42, P=0.40)$. Thus, the functional response hypothesis appears to be the most plausible explanation for increased predation rates on Orangecrowned and Virginia's nests when the two species coexist. Positive reinforcement following nest depredation may result in nest predators spending more time searching for other ground nests, increasing the chances of any nearby ground nests being depredated (Holt and Kotler 1987, Martin 1987, 1988a, c, 1996, Schmidt and Whelan 1998). In our experiment, removals of the opposite species reduced overall densities of ground nests (Fig. 5), which would reduce the likelihood of a predator finding a nest and thus receiving positive reinforcement to alter foraging behaviors. These results support a number of modeling (e.g., Holt and Kotler 1987, see also Holt and Lawton 1994), artificial nest (e.g., Martin 1988a, 1996, Schmidt and Whelan 1998), and correlative (e.g., Martin 1996, Schmidt and Whelan 1998) studies that suggest a negative interaction between coexisting species with similar nest sites, mediated by a functional response of nest predators.

\section{Fitness costs of coexistence}

Nests of both species on removal plots fledged, on average, 1.0 to $>1.5$ additional nestlings per nest, a $78-129 \%$ increase over the mean number of young fledged per nest on control plots (Fig. 7). These large differences in reproductive success between treatments suggest that both Orange-crowned and Virginia's Warblers may experience high costs of coexistence.

Orange-crowned and Virginia's Warblers did not differ in the effects of removals on the number of young fledged per nest, suggesting that both species may suffer equivalent costs of coexistence in terms of reproductive success to fledging. This may seem surprising given that Virginia's Warblers suffer reduced access to nest sites and food, as well as increased rates of nest predation when they coexist with Orange-crowned Warblers, whereas Orange-crowned Warblers suffer only higher rates of nest predation when they coexist with Virginia's Warblers. Nest predation, however, accounts for the majority of nest failures in these two species on our study plots $(87.9 \%$ of control nests in 1996, 1997, and 1998 combined), and thus the effects of nest predation are manifested through the number of young fledged per nest more so than other factors such as nest sites and food resources. Costs associated with reduced access to nest sites and food resources for Virginia's Warblers coexisting with Orangecrowned Warblers may be manifested through other components of fitness, such as postbreeding adult and juvenile survival, that were unmeasured in this study. For example, improved nest microclimate may influence physiological costs for incubating and brooding females and nestlings (see Walsberg 1985), which may in turn influence postbreeding female and juvenile survival. Similarly, reduced access to food may influence adult condition and nestling development, and in turn 
influence unmeasured post-breeding adult and juvenile survival (see references in Martin 1987). Thus, while we are unable to demonstrate differences in terms of fitness-related costs of coexistence between the two species, we believe (1) that realized fitness costs of coexistence may be higher than those suggested by reproductive success to fledging data, and (2) that other fitness costs of coexistence (e.g., in terms of adult and juvenile survival) may be higher for Virginia's when compared with Orange-crowned Warblers.

\section{Implications for community ecology}

Overall, removal experiments illustrate that (1) Orange-crowned and Virginia's Warblers do not coexist independently of each other, (2) interactions between the two species are complex, (3) interactions between the two species have fitness consequences for individuals, and (4) costs of coexistence for the two species appear to be quite large. In addition, costs of coexistence for the behaviorally dominant Orange-crowned Warbler are manifested through indirect interactions between Orange-crowned and Virginia's Warblers mediated by nest predator behavior. Costs of coexistence for the behaviorally subordinate Virginia's Warbler, conversely, appear to be manifested through both indirect interactions (e.g., through nest predators), and direct interactions (e.g., interference competition for nest sites). This pattern may be expected, given that Virginia's Warblers are subordinate in all behavioral interactions with Orange-crowned Warblers (Martin and Martin 2001), thus reducing the potential for Virginia's Warblers to directly, negatively influence coexisting Orange-crowned Warblers. This pattern of indirect interactions underlying costs to both the behaviorally dominant and subordinate competitors, and direct interactions causing costs to only the subordinate competitor, may prove to be a more general pattern in nature, although few intensive studies are available to test this association.

The asymmetrical relationship of Orange-crowned and Virginia's Warblers is a common pattern among species that segregate along environmental gradients (e.g., Connell 1961, Bovbjerg 1970, Jaeger 1971a, b, Morse 1974, Chappell 1978, Hixon 1980, Robinson and Terborgh 1995, Griffis and Jaeger 1998). The behaviorally dominant Orange-crowned Warbler occupies cooler, moister habitat that extends northward geographically and upward elevationally relative to Virginia's Warblers (see Methods: Study species). Nest site shifts illustrate that Virginia's Warblers prefer maple nest sites, but are excluded by Orange-crowned Warblers. Nonetheless, Virginia's Warblers are adapted to nest in less preferred, drier, locust/oak sites (which characterizes typical habitat across their geographic range; Dunn and Garrett 1997) in addition to preferred maple sites (Martin 1998). Orange-crowned Warblers, conversely, are not adapted to locust/oak nest sites (Martin 1998), and do not shift their nest sites out of maple habitat in the absence of Virginia's Warblers. Overall, this asymmetrical pattern (i.e., a dominant species occupies preferred habitat and is not adapted to habitat where a subordinate species occurs, while the subordinate species is adapted to a variety of habitats but is excluded from preferred habitat by a dominant competitor) may be a common pattern in nature. This pattern may be particularly prominent among closely related and/or ecologically similar species that segregate along environmental gradients on a variety of spatial scales (e.g., barnacles [Balanus, Chthamalus], Connell 1961; crayfish [Oronectes], Bovbjerg 1970; salamanders [Plethodon], Jaeger 1971a, b, Griffis and Jaeger 1998; chipmunks [Eutamias], Chappell 1978; marine fishes [Embiotica], Hixon 1980; bumblebees [Bombus], Bowers 1985; see discussion by McIntosh 1970, Morse 1974; see also Whittaker 1956, 1967, Miller 1964, Heller 1971, Terborgh 1971, Terborgh and Weske 1975, Rosenzweig 1981, Robinson and Terborgh 1995). Further work is needed to determine if this recurring pattern reflects a generalized tradeoff between competitive ability and tolerance to environmental conditions that differs among segregating species (e.g., Morse 1974, Leibold 1991).

\section{ACKNOWLEDGMENTS}

Thanks to Cameron Ghalambor, John McKay, Heather Mathewson, Chavez del Agua, Josh Tewksbury, Alex Badyaev, Alison Banks, Wes Hochachka, Mathilde Jullien, Courtney Conway, Shannon and Lindy Garner, Wendy Parsons, Paul Allen, John Lloyd, Bruce Di Labio, Christine James, Raleigh and Lois Robertson, Craig Morton, Gail Adams, Janet Martin, and Jean and Larry Martin for help at all stages of this project. Craig Morton, Rob Dobbs, Mark Banner, Mathilde Jullien, Courtney Conway, and Tina Sommer helped immensely with fieldwork. Mathilde Jullien, Chris Olson, and Mia Revels provided access to unpublished data. Scott Robinson, Eric Kofoed, an anonymous reviewer, and in particular, Burt Kotler helped to significantly improve the manuscript. Thanks to others who helped in collecting control data over the past three years: Danielle Gryskiewicz, King Jones, Paul Sweet, Mark Banner, Britt Heidinger, Sylvia Lomascolo, T. J. Fontaine, Chad Macy, Brad Straatmann, Janet Beagley, Paul Lukas, Jason Scott, Suki Lewis, Nate Christy, Viki Bisheimer, Chris Menge, Chris Olson, Elizabeth Leaf, K. C. Breen, Hope Draheim, Bill Holimon, Jen Holmes, Grace Hubenthal, Jen Kleffner, Eric Kofoed, Agustina Malizia, John May, Carolina Monmany, Eric Walters, Chris Ormond, Leo Paolini, Mercedes Rouge, Pam Watts, Jake Cseke, Jim Rivers, and Rob Dobbs. Special thanks to PRM's MSc. thesis committee: Joe Ball, Ray Callaway, and Ken Dial, and to the Cooper Ornithological Society for support and encouragement throughout this project. Thanks to Joe Ball, Vanetta Burton, Pam Tollefson, Virginia Johnston, John Malloy, Allison Perkins, and Jeff Marks at the Montana Cooperative Wildlife Research Unit for support. The Blue Ridge Ranger Station enabled research on the Mogollon Rim, while the U.S. Fish and Wildlife Service, Arizona Department of Game and Fish, and the University of Montana provided necessary permits. National Science Foundation (DEB-9527318, DEB-9707598) and USGS BBIRD funding to TEM supported this research for three years. This paper was written and revised while PRM was supported by a Bertha Morton Memorial Scholarship and a scholarship from the Natural Sciences and Engineering Research Council of Canada. 


\section{Literature Cited}

Andrews, R., and R. Righter. 1992. Colorado birds. A reference to their distribution and habitat. Denver Museum of Natural History, Denver, Colorado, USA.

Bailey, F. M. 1928. Birds of New Mexico. New Mexico Department of Game and Fish, Albuquerque, New Mexico, USA.

Bertness, M. D., and R. Callaway. 1994. Positive interactions in communities. Trends in Ecology and Evolution 9:191193

Bovbjerg, H. 1970. Ecological isolation and competitive exclusion in two crayfish (Orconectes virillis and Orconectes immunis). Ecology 51:225-236.

Bowers, M. A. 1985. Experimental analysis of competition between two species of bumble bees (Hymenoptera: Apidae). Oecologia 67:224-230.

Calder, W. A. 1973. Microhabitat selection during nesting of hummingbirds in the Rocky Mountains. Ecology 54:127134.

Chappell, M. A. 1978. Behavioral factors in the altitudinal zonation of chipmunks (Eutamias). Ecology 59:565-579.

Cody, M. L. 1974. Competition and the structure of bird communities. Princeton University Press, Princeton, New Jersey, USA.

Cody, M. L., and J. M. Diamond, editors. 1975. Ecology and evolution of communities. Harvard University Press, Cambridge, Massachusetts, USA.

Connell, J. H. 1961. The influence of interspecific competition and other factors on the distribution of the barnacle Chthamalus stellatus. Ecology 42:710-723.

Connell, J. H. 1980. Diversity and the coevolution of competitors, or the ghost of competition past. Oikos 35:131138.

Connell, J. H. 1983. On the prevalence and relative importance of interspecific competition: evidence from field experiments. American Naturalist 122:661-696.

Diamond, J. M. 1973. Distributional ecology of New Guinea birds. Science 179:759-769.

Diamond, J. M. 1978. Niche shifts and the rediscovery of interspecific competition. American Scientist 66:322-331.

Dobson, A. P., and P. J. Hudson. 1986. Parasites, disease and the structure of ecological communities. Trends in Ecology and Evolution 1:11-15.

Dunn, J. L., and K. L. Garrett. 1997. A field guide to warblers of North America. Houghton Mifflin Company, Boston, Massachusetts, USA.

Dunning, J. B., Jr. 1993. CRC handbook of avian body masses. CRC Press, Boca Raton, Florida, USA

Fauth, J. E., J. Bernardo, M. Camara, W. J. Resetarits, Jr., J. van Buskirk, and S. A. McCollum. 1996. Simplifying the jargon of community ecology: a conceptual approach American Naturalist 147:282-286.

Gause, G. F. 1932. Experimental studies on the struggle for existence. I. Mixed population of two species of yeast. Journal of Experimental Biology 9:389-402.

Gleason, H. A. 1926. The individualistic concept of the plant association. Torrey Botanical Club Bulletin 53:7-26.

Grace, J. B., and D. Tilman. 1990. Perspectives on plant competition. Academic Press, New York, New York, USA

Graveland, J., R. van der Wal, J. H. van Balen, and A. J. van Noordwijk. 1994. Poor reproduction in forest passerines from decline of snail abundance on acidified soils. Nature 368:446-448.

Greene, E., W. Davison, and V. Muehter. 1998. Steller's Jay (Cyanocitta stelleri). Pages 1-20 in A. Poole and F. Gill, editors. The birds of North America, Number 343. The Academy of Natural Sciences, Philadelphia, Pennsylvania, USA, and The American Ornithologists' Union, Washington, D.C., USA.

Griffis, M. R., and R. G. Jaeger. 1998. Competition leads to an extinction-prone species of salamander: interspecific territoriality in a metapopulation. Ecology 79:2494-2502

Gustafsson, L. 1987. Interspecific competition lowers fitness in Collared Flycatchers, Ficedula albicollis: an experimental demonstration. Ecology 68:291-296.

Hairston, N. G. 1989. Ecological experiments: purpose, design, and execution. Cambridge University Press, New York, New York, USA.

Heller, H. C. 1971. Altitudinal zonation of chipmunks (Eutamias): interspecific aggression. Ecology 52:312-319.

Hensler, G. L., and J. D. Nichols. 1981. The Mayfield method of estimating nesting success: a model, estimators and simulation results. Wilson Bulletin 93:42-53.

Hines, J. E., and J. R. Sauer. 1989. Program CONTRAST: a general program for the analysis of several survival or recovery rate estimates. U.S. Fish and Wildlife Service, Fish and Wildlife Technical Report 24.

Hixon, M. A. 1980. Competitive interactions between California reef fishes of the genus Embiotica. Ecology 61:918931.

Hochberg, Y. 1988. A sharper Bonferroni procedure for multiple tests of significance. Biometrika 74:800-802.

Holt, R. D. 1977. Predation, apparent competition, and the structure of prey communities. Theoretical Population Biology 12:197-229.

Holt, R. D., and B. P. Kotler. 1987. Short-term apparent competition. American Naturalist 130:412-430.

Holt, R. D., and J. H. Lawton. 1994. The ecological consequences of shared natural enemies. Annual Review of Ecology and Systematics 25:495-520.

Jaeger, R. G. 1971a. Competitive exclusion as a factor influencing the distributions of two species of terrestrial salamanders. Ecology 52:535-546.

Jaeger, R. G. 1971b. Moisture as a factor influencing the distributions of two species of terrestrial salamanders. Oecologia 6:191-207.

James, F. C., R. F. Johnston, N. O. Wamer, G. J. Niemi, and W. J. Boecklen. 1984. The Grinnelian niche of the Wood Thrush. American Naturalist 124:17-47.

James, S. 1991. Approximate multinomial probabilities applied to correlated multiple endpoints in clinical trials. Statistics in Medicine 10:1123-1136.

Johnson, D. H. 1979. Estimating nest success: the Mayfield method and an alternative. Auk 96:651-661.

Leibold, M. A. 1991. Trophic interactions and habitat segregation between competing Daphnia species. Oecologia 86:510-520.

Ligon, J. S. 1961. New Mexico birds and where to find them. University of New Mexico Press, Albuquerque, New Mexico, USA

Lotka, A. J. 1925. Elements of physical biology. Williams and Wilkins, Baltimore, Maryland, USA.

MacArthur, R. H. 1958. Population ecology of some warblers in northeastern coniferous forests. Ecology 39:599-619.

MacArthur, R. H. 1972. Geographical ecology. Patterns in the distribution of species. Harper and Row, New York, New York, USA

Mac Nally, R. C. 1983. On assessing the significance of interspecific competition to guild structure. Ecology 64: $1646-1652$.

Martin, P. R., and T. E. Martin. 2001. Behavioral interactions between coexisting species: song playback experiments with wood warblers. Ecology 82:207-218.

Martin, T. E. 1986. Competition among breeding birds: on the importance of considering processes at the level of the individual. Current Ornithology 4:181-210.

Martin, T. E. 1987. Food as a limit on breeding birds: a lifehistory perspective. Annual Review of Ecology and Systematics 18:453-487.

Martin, T. E. 1988a. On the advantage of being different: 
nest predation and the coexistence of bird species. Proceedings of the National Academy of Sciences (USA) 85: 2196-2199.

Martin, T. E. 1988b. Habitat and area effects on forest bird assemblages: is nest predation an influence? Ecology 69 : 74-84.

Martin, T. E. 1988c. Processes organizing open-nesting bird assemblages: competition or nest predation? Evolutionary Ecology 2:37-50.

Martin, T. E. 1993. Nest predation and nest sites: New perspectives on old patterns. BioScience 43:523-532.

Martin, T. E. 1995. Avian life history evolution in relation to nest sites, nest predation, and food. Ecological Monographs 65:101-127.

Martin, T. E. 1996. Fitness costs of resource overlap among coexisting bird species. Nature 380:338-340.

Martin, T. E. 1998. Are microhabitat preferences of coexisting species under selection and adaptive? Ecology 79: 656-670.

Martin, T. E. 2001. Abiotic vs. biotic influences on habitat selection of coexisting species: climate change impacts? Ecology 82:175-188.

Martin, T. E., and J. J. Roper. 1988. Nest predation and nest site selection of a western population of the Hermit Thrush. Condor 90:51-57.

Mayfield, H. 1975. Suggestions for calculating nest success. Wilson Bulletin 87:456-466.

McIntosh, R. 1970. Community, competition, and adaptation. Quarterly Review of Biology 45:259-280.

McPeek, M. A., and T. E. Miller. 1996. Special feature. Evolutionary biology and community ecology. Ecology 77: 1319-1320.

Miller, R. S. 1964. Ecology and distribution of pocket gophers (Geomyidae) in Colorado. Ecology 45:256-272.

Morse, D. H. 1974. Niche breadth as a function of social dominance. American Naturalist 108:818-830.

Peterson, R. T. 1990. A field guide to western birds. Houghton Mifflin Company, Boston, Massachusetts, USA.

Rice, W. R. 1989. Analyzing tables of statistical tests. Evolution 43:223-225.

Robinson, S. K., and J. Terborgh. 1995. Interspecific aggression and habitat selection by Amazonian birds. Journal of Animal Ecology 64:1-11.

Rosenzweig, M. L. 1981. A theory of habitat selection. Ecology 62:327-335.

Schmidt, K. A., and C. J. Whelan. 1998. Predator-mediated interactions between and within guilds of nesting songbirds: experimental and observational evidence. American Naturalist 152:393-402.

Schoener, T. W. 1974. Resource partitioning in ecological communities. Science 185:27-39.

Schoener, T. W. 1982. The controversy over interspecific competition. American Scientist 70:586-595.

Schoener, T. W. 1983. Field experiments on interspecific competition. American Naturalist 122:240-285.

Scott, S. L., editor. 1987. Field guide to the birds of North
America. Second edition. The National Geographic Society, Washington, D.C., USA.

Shaw, R. G., and T. Mitchell-Olds. 1993. ANOVA for unbalanced data: an overview. Ecology 74:1638-1645.

Sogge, M. K., W. M. Gilbert, and C. van Riper III. 1994. Orange-crowned Warbler (Vermivora celata). Pages 1-20 in A. Poole and F. Gill, editors. The birds of North America, Number 101. The Academy of Natural Sciences, Philadelphia, Pennsylvania, USA, and The American Ornithologists' Union, Washington, D.C., USA.

Taylor, R. C. 1995. A birder's guide to southeastern Arizona. American Birding Association, Colorado Springs, Colorado, USA.

Terborgh, J. 1971. Distribution on environmental gradients: theory and a preliminary interpretation of distributional patterns in the avifauna of the Cordillera Vilcabamba, Peru. Ecology 52:23-40.

Terborgh, J., and J. S. Weske. 1975. The role of competition in the distribution of Andean birds. Ecology 56:562-576.

Tilman, D. 1982. Resource competition and community structure. Princeton University Press, Princeton, New Jersey, USA.

Underwood, T. 1986. The analysis of competition by field experiments. Pages 240-268 in J. Kikkawa and D. J. Anderson, editors. Community ecology. Patterns and process. Blackwell Scientific Publications, Melbourne, Australia.

Volterra, V. 1926. Fluctuations in the abundance of a species considered mathematically. Nature 118:558-560.

Walker, E. P. 1964. Mammals of the world. Volume II. The Johns Hopkins Press, Baltimore, Maryland, USA.

Walsberg, G. E. 1981. Nest-site selection and the radiative environment of the Warbling Vireo. Condor 83:86-88.

Walsberg, G. E. 1985. Physiological consequences of microhabitat selection. Pages 389-413 in M. L. Cody, editor. Habitat selection in birds. Academic Press, Inc., New York, New York, USA.

Whittaker, R. H. 1956. Vegetation of the Great Smoky Mountains. Ecological Monographs 26:1-80.

Whittaker, R. H. 1967. Gradient analysis of vegetation. Biological Reviews 42:207-264.

Wiens, J. A. 1983. Avian community ecology: an iconoclastic view. Pages 355-403 in A. H. Brush and G. A. Clark, Jr., editors. Perspectives in ornithology. Cambridge University Press, Cambridge, UK.

Wiens, J. A. 1989a. The ecology of bird communities. Volume 1. Foundations and patterns. Cambridge University Press, Cambridge, UK.

Wiens, J. A. 1989b. The ecology of bird communities. Volume 2. Processes and variations. Cambridge University Press, Cambridge, UK.

Wooton, J. T. 1994. The nature and consequences of indirect effects. Annual Review of Ecology and Systematics 25: 443-466.

Zerba, E., and M. L. Morton. 1983. The rhythm of incubation from egg laying to hatching in Mountain White-crowned Sparrows. Ornis Scandinavica 14:188-197. 